\title{
Identification of minimal human MHC-restricted CD8+ T-cell epitopes within the Plasmodium falciparum circumsporozoite protein (CSP)
}

Martha Sedegah ${ }^{1 *}$, Yohan Kim², Harini Ganeshan ${ }^{1}$, Jun Huang ${ }^{1}$, Maria Belmonte', Esteban Abot ${ }^{1}$, Jo Glenna Banania ${ }^{1}$, Fouzia Farooq ${ }^{1}$, Shannon McGrath', Bjoern Peters², Alessandro Sette², Lorraine Soisson ${ }^{4}$, Carter Diggs ${ }^{4}$, Denise L Doolan ${ }^{3}$, Cindy Tamminga', Eileen Villasante ${ }^{1}$, Michael R Hollingdale ${ }^{1}$ and Thomas L Richie

\begin{abstract}
Background: Plasmodium falciparum circumsporozoite protein (CSP) is a leading malaria vaccine candidate antigen, known to elicit protective antibody responses in humans (RTS,S vaccine). Recently, a DNA prime / adenovirus (Ad) vector boost vaccine encoding CSP and a second P. falciparum antigen, apical membrane antigen-1, also elicited sterile protection, but in this case associated with interferon gamma ELISpot and CD8+ T cell but not antibody responses. The finding that CSP delivered by an appropriate vaccine platform likely elicits protective cell-mediated immunity provided a rationale for identifying class I-restricted epitopes within this leading vaccine candidate antigen.

Methods: Limited samples of peripheral blood mononuclear cells from clinical trials of the Ad vaccine were used to identify CD8+ T cell epitopes within pools of overlapping 15 mer peptides spanning portions of CSP that stimulated recall responses. Computerized algorithms (NetMHC) predicted 17 minimal class I-restricted 9-10mer epitopes within fifteen 15 mers positive in ELISpot assay using PBMC from 10 HLA-matched study subjects. Four additional epitopes were subsequently predicted using NetMHC, matched to other study subjects without initial 15 mer ELISpot screening. Nine of the putative epitopes were synthesized and tested by ELISpot assay, and six of these nine were further tested for CD8+ T cell responses by ELISpot CD4+ and CD8+ T cell-depletion and flow cytometry assays for evidence of CD8+ T cell dependence.
\end{abstract}

Results: Each of the nine putative epitopes, all sequence-conserved, recalled responses from HLA-matched CSP-immunized research subjects. Four shorter sequences contained within these sequences were identified using NetMHC predictions and may have contributed to recall responses. Five (9-10mer) epitopes were confirmed to be targets of CD8+ T cell responses using ELISpot depletion and ICS assays. Two 9mers among these nine epitopes were each restricted by two HLA supertypes (A01/B07; A01A24/A24) and one 9mer was restricted by three HLA supertypes (A01A24/A24/B27) indicating that some CSP class I-restricted epitopes, like DR epitopes, may be HLA-promiscuous.

Conclusions: This study identified nine and confirmed five novel class I epitopes restricted by six HLA supertypes, suggesting that an adenovirus-vectored CSP vaccine would be immunogenic and potentially protective in genetically diverse populations.

Keywords: Malaria, Vaccine, Circumsporozoite protein, ELISpot, Flow cytometry, NetMHC, Epitope mapping, Class I restriction, Localization

\footnotetext{
* Correspondence: martha.sedegah@med.navy.mil

${ }^{1}$ US Military Malaria Vaccine Program, Naval Medical Research Center, Walter Reed Army Institute of Research, Silver Spring, MD, USA

Full list of author information is available at the end of the article
} 


\section{Background}

The circumsporozoite protein (CSP) is the main antigenic component of several candidate malaria vaccines, including the RTS,S vaccine currently undergoing Phase 3 testing in sub-Saharan Africa. RTS,S induces anti-CSP antibodies thought to mediate protection by targeting sporozoites, inhibiting motility and hepatocyte invasion [1]. This proposed mechanism is supported by the finding that both antibody and CD4+ T cell responses to CSP correlate with protection [1]. CD8+ $\mathrm{T}$ cell responses, however, have not been consistently demonstrated in individuals vaccinated with RTS,S $[1,2]$. Thus it is not clear whether RTS,S additionally targets the liver stages of Plasmodium, where immunity appears to be CD8+ T cell dependent [3]. CSP is carried into hepatocytes by invading sporozoites [4] and is expressed as peptides on the surface of the infected hepatocytes in the context of MHC Class I, potentially allowing recognition by CSP-specific CD8+ T cells [5]. Vaccine platforms such as adenovirus vectors promoting the induction of CD8+ T cell responses to CSP or other antigens expressed on the surface of infected hepatocytes might therefore improve protection against liver stage parasites [6].

To this aim, a replication-deficient adenovirus (Ad)vectored vaccine encoding Plasmodium falciparum CSP (PfCSP) (NMRC-MV-Ad-PfC, or Ad-C) was tested in humans. The vaccine, based on human adenovirus serotype 5 , was tested by itself and in combination with a second Ad vector encoding apical membrane antigen-1 (AMA1) (NMRC-MV-Ad-PfA, or Ad-A). Both Ad-C and Ad-CA (the combination of Ad-C and Ad-A) vaccines elicited robust CD8+ $T$ cell responses against both antigens [7-9], similar to other Ad-based vaccines under development for different pathogens [10]. AMA1 was added to CSP because AMA1 is likewise involved in hepatocyte invasion by the malaria parasite [11], and AMA1 peptides may similarly be expressed on the surface of infected hepatocytes. Simultaneous expression of peptides derived from both antigens could facilitate targeting by effector CD8+ T cells. To further enhance cell-mediated responses, the combination Ad-CA vaccine was primed with three doses of DNA expressing CSP and AMA1. The resulting DNA/Ad regimen induced sterile protection against controlled human malaria infection (CHMI) in 27\% of immunized volunteers, with protection significantly correlated with CD8+ T cell interferon-gamma responses [12]. Antibody responses were relatively low, and did not correlate with protection, consistent with the hypothesis that CD8+ T cells may be the primary immune effector targeting liver stage parasites in humans [3].

The aim of the current study was to identify the class I $\mathrm{CD} 8+\mathrm{T}$ cell epitopes in CSP recognized by the cellmediated responses to the $\mathrm{Ad}-\mathrm{C}$ and Ad-CA vaccines.
Such epitopes could be used in the design of epitopebased vaccines, and responses to these epitopes could be assessed prospectively as potential correlates of protection induced by the DNA/Ad vaccine or other CSP-based vaccines. Previously, 14 class I-restricted epitopes were identified within AMA1, using a combination of predictive algorithms (NetMHC [13]) and cellular immunoassays [14]. The current study applied similar methods to map class I-restricted epitopes in CSP.

PfCSP (3D7 strain) contains 397 amino acids (aa), with the N-terminal region spanning aa 1-104, the central repeat region spanning aa 105-272, and the C-terminal region spanning aa 273-397 (Figure 1). The C-terminal region contains the thrombospondin-like type 1 repeat domain [15] overlapping the Th2R and Th3R T epitope regions [16]. While the RTS,S vaccine contains aa 207395 [17], and therefore lacks the $\mathrm{N}$-terminal region [18], the Ad-C vaccine is full length except for a deletion of 16 repeats (64 aa) between 209-272 (leaving 26 repeats intact), and the insertion of a 23 aa tail at the Cterminus, derived from the 3'-noncoding bovine growth hormone polyadenylation sequence $[7,8]$.

A summary of previously published DR-restricted epitopes identified in CSP is shown in Figure 1. These DR-restricted epitopes were identified using malariaendemic volunteers or volunteers immunized with radiation-attenuated sporozoites (RAS). Three DRrestricted epitopes, D43, D44 and D50 [19-21], were originally characterized using class II binding assays to identify peptides that recalled proliferative responses from individuals living in a malaria-endemic area; D10, D45, D49, Th2R and Th3R [22] were characterized using overlapping peptides to recall proliferative responses, likewise from individuals living in malaria-endemic areas; and CS.T3 was identified using proliferation assays testing samples from volunteers immunized with RAS [23].

Previously published class I-restricted CSP epitopes are also shown in Figure 1, and have been identified in both the $\mathrm{N}$ - and C-terminal regions. D1, D2, D3, and D6 were identified using class I binding assays to identify peptides that induced cytotoxic recall activities from volunteers immunized with RAS and from malaria-endemic volunteers [24,25]; D4 was identified using peptides to recall proliferation responses from malaria-endemic volunteers [26]; and D5, D7, D8 and D9 were characterized using short peptides designed to match the HLA of malaria-endemic volunteers $[27,28]$. D5 and D9 have been tested in mice for induction of cytotoxic $\mathrm{T}$ cell responses [29]. More recently, D4, D5 and D6 were shown to recall interferon-gamma responses in ELISpot assays using PBMCs from individuals living in a malariaendemic region of Ghana [30].

HLA alleles have been grouped into nine supertypes that are clusters of alleles with similar peptide-binding 


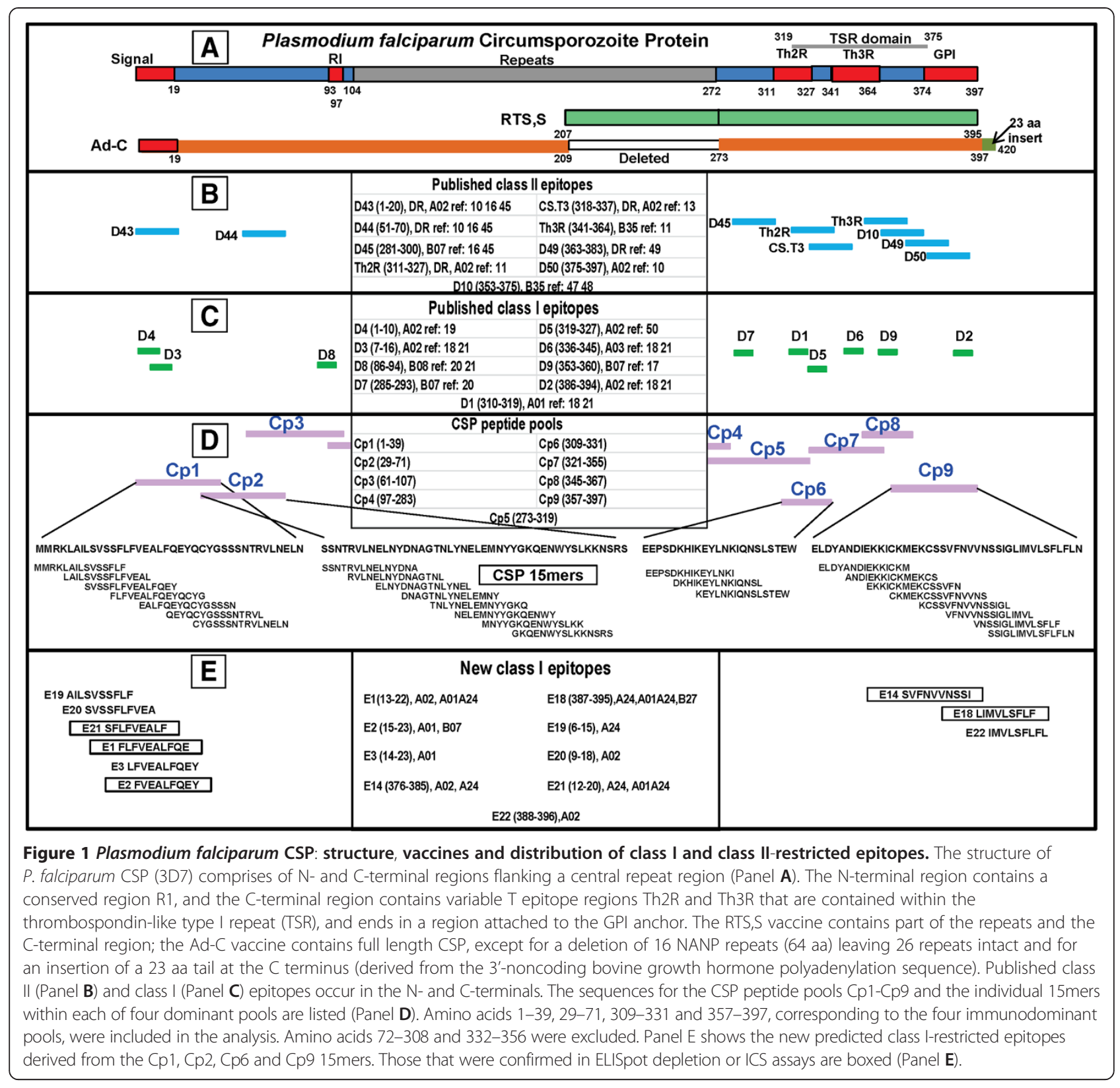

motifs [31], and the majority of HLA alleles fit these supertypes [31-33]. Based on algorithms that predict binding to MHC molecules, measured as 50\% inhibitory concentration $\left(\mathrm{IC}_{50}\right)$ values expressed as nanomolar (nM) [34], a meta-analysis using an affinity cut-off of $500 \mathrm{nM}$ predicted that $52 \%$ of a panel $P$. falciparum peptides bound to HLA A*02:01 [35], and led to the development of publically available algorithms that are specific for class I and class II types [35]. The outcomes of these and similar studies led to the establishment of the Immune Epitope Database and Analysis Resource (IEDB) that contains open access data and analytical tools for malaria and a wide range of other organisms [36]. Class II-restricted epitopes are well known to be promiscuous, binding to multiple HLA alleles [37], including DR-restricted epitopes in CSP [21]. Similar promiscuity in class I-restricted epitopes has been described for malaria antigens including CSP [24] and has been extended to include epitopes from other organisms [38,39]. Recently, analysis of the IEDB data base suggests that $>50 \%$ of HLA class I-restricted ligands bind to two or more HLA molecules often spanning different supertypes [40].

To conduct the mapping studies of CSP epitopes, peripheral blood mononuclear cells (PBMC) were selected from limited supplies of frozen specimens previously collected from volunteers immunized with Ad-C or AdCA in three different trials [7-9]. Nine CSP peptide pools containing three to 12 overlapping 15 mer peptides had 
been used during the original analysis of these clinical trials to characterize responses in ELISpot assays and flow cytometry, with four pools giving the highest responses [7]. Since the numbers of frozen PBMC from these three trials were limited, only these four CSP peptide pools were used for epitope mapping, and for the same reason (limited PBMC supplies), previously described class I epitopes were not tested.

\section{Methods}

\section{Vaccines and trial design}

The vaccine used in this study was either the CSPencoding Ad vector alone (Ad-C) or the same in combination with AMA1-encoding Ad vector (Ad-CA), in three different clinical trials (Figure 2). In the first trial, six volunteers were immunized with $2 \times 10^{10}$ particle units $(\mathrm{pu})$ of both adenovectors (Ad-CA) as a single intramuscular dose, but there was no controlled human malaria infection (CHMI) to determine efficacy in this small safety study [7]. In the second trial, 18 volunteers were similarly immunized once with $2 \times 10^{10} \mathrm{pu}$ of Ad-CA, and in this trial they underwent CHMI by bite of P. falciparum-infected mosquitoes [9]. In the third trial, volunteers were immunized twice with $1 \times 10^{10} \mathrm{pu}$ of Ad-C alone at week 0 (15 volunteers) and week 16 (14 volunteers). These research subjects also underwent CHMI by bite of P. falciparuminfected mosquitoes [8]. While none of the volunteers in the two challenge studies was sterilely protected against malaria (contrasting with the trial where DNA was first used to prime the response), the Ad-alone vaccine regimens were strongly immunogenic for $\mathrm{CD} 8+$ and CD4+ T cell responses.

\section{Volunteers and HLA typing}

HLA molecular typing for HLA-A and HLA-B loci was performed by the Department of Defense Bone Marrow Donor Program using specific oligonucleotide probes to amplify HLA Class I genes. Typing included a list of allelic codes from which it was possible to assign each volunteer to an HLA-A or HLA-B allele group using code lists as previously described [14]. Each HLA-A or HLA-B allele group was then assigned to HLA A or HLA B supertypes according to published nomenclatures. All 17 volunteers from the three trials used in this study, and their HLA A and B allele groups, are shown in Table 1.

\section{Peripheral blood mononuclear cells (PBMC)}

The PBMC used in this study for epitope mapping were collected 19-28 days following Ad administration, a period corresponding to the peak response. In a few cases where samples were insufficient, collections from 28 days post challenge (56 days post Ad administration) were used instead, as responses to this vaccine in a prior study persisted for at least 12 months in most research subjects [7]. In summary, the PBMC samples were obtained from the following time points: trial 1 (Ad-CA, no CHMI), 28 days following immunization; trial 2 (AdCA, with CHMI), 22-23 days after immunization and 28 days after challenge; trial 3 (Ad-C administered twice

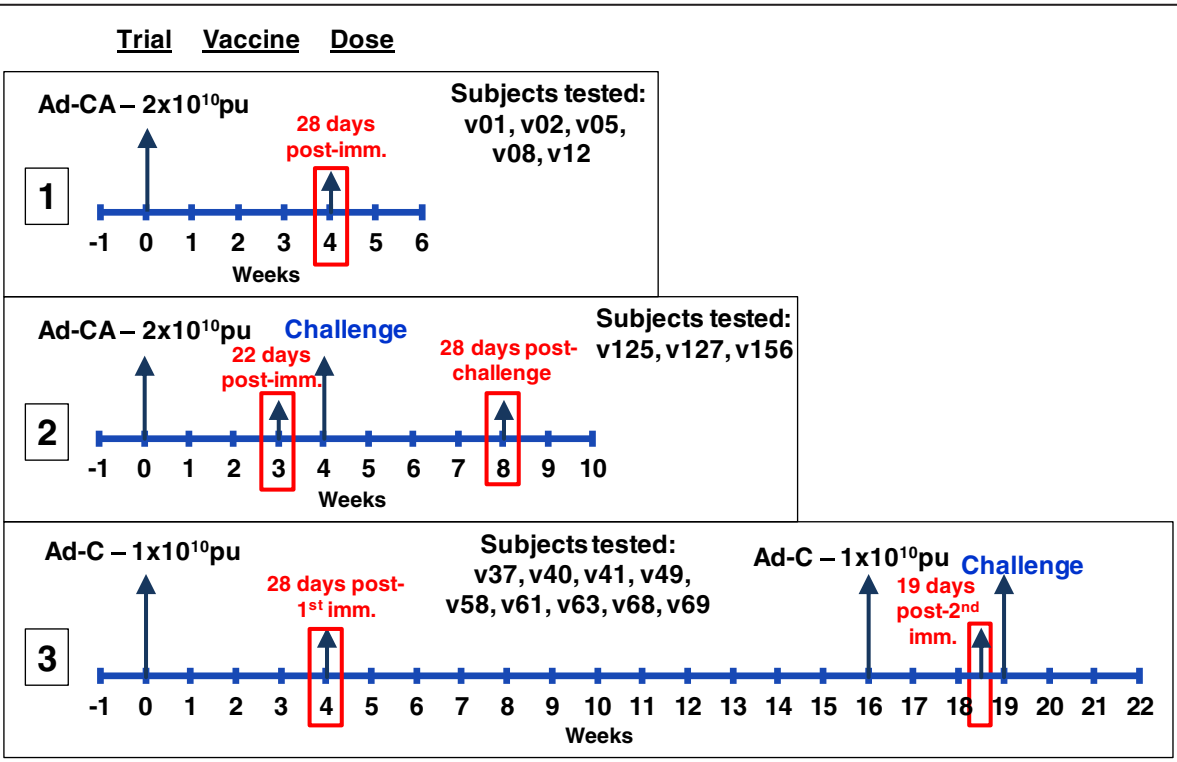

Figure 2 Vaccine trials with adenovirus vectored CSP used to map CSP epitopes. Three trials using adenovirus-vectored CSP (Ad-C) were performed: trial 1 used Ad-C combined with adenovirus-vectored AMA (Ad-A) given as one immunization (Ad-CA) to six subjects without CHMl; trial 2 used the same dose of Ad-CA given to 18 subjects followed by CHMl four weeks later; trial 3 used Ad-C administered twice 16 weeks apart (to 15 and 14 subjects respectively) followed by CHMI four weeks later. Collection points for PBMC used in this study are shown in boxes. The 17 subjects that were used in this study are identified by trial. Challenge $=\mathrm{CHMl}$. 
Table 1 Volunteer HLA A and B allele groups and supertypes

\begin{tabular}{|c|c|c|c|c|c|c|c|c|c|c|c|c|c|}
\hline \multirow{2}{*}{ Vaccine } & \multirow{2}{*}{ Vol. } & \multicolumn{3}{|c|}{ Strategy } & \multirow{2}{*}{ Trial } & \multirow{2}{*}{$\begin{array}{l}\text { HLA-A1 } \\
\text { allele group }\end{array}$} & \multirow{2}{*}{$\begin{array}{c}\text { HLA-A2 } \\
\text { allele group }\end{array}$} & \multirow{2}{*}{$\begin{array}{c}\text { HLA-B1 } \\
\text { allele group }\end{array}$} & \multirow{2}{*}{$\begin{array}{c}\text { HLA-B2 } \\
\text { allele group }\end{array}$} & \multirow{2}{*}{$\begin{array}{c}\text { HLA-A1 } \\
\text { supertype }\end{array}$} & \multirow{2}{*}{$\begin{array}{c}\text { HLA-A2 } \\
\text { supertype }\end{array}$} & \multirow{2}{*}{$\begin{array}{c}\text { HLA-B1 } \\
\text { supertype }\end{array}$} & \multirow{2}{*}{$\begin{array}{l}\text { HLA-B2 } \\
\text { supertype }\end{array}$} \\
\hline & & $\overline{1 A}$ & 1B & $\overline{2}$ & & & & & & & & & \\
\hline \multirow[t]{5}{*}{$\mathrm{Ad}-\mathrm{CA}$} & $\mathrm{v} 1$ & $x$ & & & 1 & $A^{*} 02: 01$ & $A^{*} 26: 01$ & $B^{*} 18: 01$ & $B * 44: 02$ & A02 & $\mathrm{A} 01$ & B44 & B44 \\
\hline & v2 & $x$ & & & 1 & $A^{*} 01: 01$ & $A^{*} 02: 01$ & $B^{*} 08: 01$ & $B * 44: 02$ & $\mathrm{~A} 01$ & A02 & B08 & B44 \\
\hline & v5 & $\mathbf{x}$ & & & 1 & $A^{* 01: 01}$ & $A^{*} 68: 02$ & $B^{*} 08: 01$ & $B^{*} 14: 02$ & A01 & A02 & B08 & B27 \\
\hline & v8 & $\mathbf{x}$ & & & 1 & $A^{*} 68: 01$ & $A^{*} 68: 02$ & $B^{*} 14: 02$ & $B^{*} 48: 01$ & $\mathrm{~A} 03$ & A02 & B27 & B27 \\
\hline & $\mathrm{v} 12$ & $\mathbf{x}$ & & & 1 & $A^{*} 30: 02$ & $A^{*} 68: 01$ & $B^{*} 18: 01$ & $B * 58: 02$ & $\mathrm{~A} 01$ & $\mathrm{~A} 03$ & B44 & B58 \\
\hline \multirow[t]{3}{*}{$\mathrm{Ad}-\mathrm{CA}$} & v125 & & & $x$ & 2 & $A^{*} 02: 01$ & $A^{*} 11: 01$ & $B^{*} 35: 01$ & $B * 52: 01$ & $\mathrm{~A} 02$ & A03 & B07 & B62 \\
\hline & v127 & & $x$ & & 2 & $A^{*} 01: 01$ & $A^{*} 24: 02$ & $B^{*} 08: 01$ & $B^{*} 44: 05$ & $\mathrm{~A} 01$ & A24 & B08 & B44 \\
\hline & v156 & & $x$ & $\mathbf{x}$ & 2 & $A^{*} 03: 01$ & $A^{*} 29: 02$ & $B^{*} 15: 03$ & $B * 58: 02$ & $\mathrm{~A} 03$ & $\mathrm{~A} 01 \mathrm{~A} 24$ & B27 & B58 \\
\hline \multirow[t]{9}{*}{$A d-C$} & v37 & & $x$ & $x$ & 3 & $A^{*} 23: 01$ & $A^{*} 68: 02$ & $B^{*} 15: 03$ & $B * 53: 01$ & A24 & A02 & B27 & B07 \\
\hline & v40 & & $x$ & $x$ & 3 & $A^{*} 23: 01$ & $A^{*} 29: 02$ & $B * 52: 01$ & $B * 53: 01$ & A24 & A01 & B62 & B07 \\
\hline & v41 & $\mathbf{x}$ & & & 3 & $A^{*} 02: 01$ & $A^{*} 31: 01$ & $B^{*} 07: 02$ & $B * 35: 01$ & $\mathrm{~A} 02$ & $\mathrm{~A} 03$ & B07 & B07 \\
\hline & v49 & $\mathbf{x}$ & & & 3 & $A^{*} 33: 01$ & $A^{*} 74: 01$ & $B^{*} 15: 03$ & $B^{*} 15: 03$ & $\mathrm{~A} 03$ & A03 & B27 & B27 \\
\hline & v58 & $x$ & $x$ & & 3 & $A^{*} 02: 01$ & $A^{*} 24: 02$ & $B^{*} 08: 01$ & $B * 38: 02$ & A02 & A24 & B08 & $\mathrm{B} 27^{1}$ \\
\hline & v61 & $\mathbf{x}$ & & & 3 & $A^{*} 02: 01$ & $A^{*} 02: 01$ & $B^{*} 38: 01$ & $B^{*} 44: 02$ & A02 & A02 & B27 & B44 \\
\hline & v63 & & & $\mathbf{x}$ & 3 & $A^{*} 11: 01$ & $A^{*} 24: 03$ & $B * 40: 01$ & $B * 51: 04$ & $\mathrm{~A} 03$ & A24 & B44 & B07 \\
\hline & v68 & & & $x$ & 3 & $A^{*} 24: 02$ & $A^{*} 30: 01$ & $B * 13: 02$ & $B^{*} 14: 02$ & A24 & A01 A03 & $B 62^{1}$ & B27 \\
\hline & v69 & $\mathbf{x}$ & $x$ & & 3 & $A^{*} 30: 02$ & $A^{*} 34: 02$ & $B^{*} 14: 02$ & $B^{*} 35: 01$ & A01 & $\mathrm{A} 03$ & B27 & B07 \\
\hline
\end{tabular}

The volunteers from whom PBMC were available and were tested are shown. Trial 1 (no CHMI): five of six volunteers immunized with Ad-CA were used (reference 7). Trial 2 (with CHMI): three of 17 volunteers immunized with Ad-CA and challenged by bite of $P$. falciparum-infected mosquitoes were used (Tamminga, in press). Trial 3 (with CHMI): nine of 11 volunteers immunized with Ad-C and challenged by bite of $P$. falciparum-infected mosquitoes were used (reference 8 ). The table also identifies the ten volunteers with best available PBMC that were included in the broad screen of all 15-mer peptides from the four dominant pools (column $1 \mathrm{~A})$, the six volunteers used to confirm recognition of minimal epitopes predicted within positive 15 -mers $($ column $1 \mathrm{~B})(1 \mathrm{~A}+1 \mathrm{~B}=$ strategy 1$)$, and the six volunteers used to confirm recognition of minimal epitopes predicted within 15-mers without the initial screen (strategy 2).

${ }^{1}$ As classified in reference [42].

followed by CHMI), 28 days and 19 days after the first and second immunizations, respectively. These time points are indicated in Figure 2 and, where appropriate, in the Tables (see below). Previous studies have confirmed that recall $\mathrm{T}$ cell responses measured by ELISpot assay are able to be detected using cryopreserved PBMCs although such responses are generally of lower magnitude than fresh cells [14].

\section{Peptides and peptide pools}

Sixty-five 15mer peptides overlapping by 11 amino acids and spanning the full length of CSP (3D7 strain) were synthesized commercially (Mimotopes, VIC, Australia, $>80 \%$ purity) and grouped into nine peptide pools containing three to 12 peptides in each (Figure 1). Four of these pools (Cp1, Cp2, Cp6, and Cp9) containing 26 peptides (Table 2) elicited the highest ELISpot responses among the volunteers who received the Ad-C or Ad-CA vaccines [7] (Figure 3) and were selected for this study. Minimal (9-10mer) epitopes were synthesized by Alpha Diagnostics Intl Inc, San Antonio, TX, USA (>91\% purity).

\section{Strategies to identify class I-restricted CSP epitopes}

Two strategies were used to identify class I epitopes within these four immunodominant pools.
Strategy 1: Each of the 2615 mers contained within the four pools was tested individually by ELISpot assay using PBMC from 10 selected volunteers with sufficient PBMC available. 15 mers positive by this screen were analysed by NetMHC to identify putative class I-restricted epitopes, some of which were then synthesized (see below). Depending upon PBMC availability, the putative epitopes were tested in HLA-matched volunteers by ELISpot assays for ability to recall interferon-gamma responses.

Strategy 2: Because there were not sufficient frozen PBMC available to extend the analysis using the comprehensive ELISpot screening with 26 15mers to additional volunteers, NetMHC predictions were used directly to identify class I-restricted epitopes within 15mers that could be matched to six additional volunteers with robust responses against the parent pool. Some of these minimal epitopes were also synthesized and tested in ELISpot assays. As a control, some predicted epitopes were tested with non-HLA-matched volunteers for whom PBMC were available.

Ex vivo IFN- $\gamma$ enzyme-linked immunospot (ELISpot) assays IFN- $\gamma$ ELISpot assays were conducted as previously described $[14,41]$. Cryopreserved PBMC were suspended in $100 \mu \mathrm{L}$ complete medium and stimulated with CSP 
Table 2 CSP peptides used in ELISPOT and ICS assays

\begin{tabular}{|c|c|c|c|c|}
\hline Pool & Amino acids & $15 \mathrm{mer}$ & Amino acids & Sequence \\
\hline \multirow[t]{7}{*}{ Cp1 } & $1-39$ & $\mathrm{C} 1$ & $1-15$ & MMRKLAILSVSSFLF \\
\hline & & $\mathrm{C} 2$ & $5-19$ & LAILSVSSFLFVEAL \\
\hline & & $\mathrm{C} 3$ & $9-23$ & SVSSFLFVEALFQEY \\
\hline & & $\mathrm{C} 4$ & $13-27$ & FLFVEALFQEYQCYG \\
\hline & & $\mathrm{C} 5$ & $17-31$ & EALFQEYQCYGSSSN \\
\hline & & C6 & $21-35$ & QEYQCYGSSSNTRVL \\
\hline & & $\mathrm{C7}$ & $25-39$ & CYGSSSNTRVLNELN \\
\hline \multirow[t]{8}{*}{ Cp2 } & $29-71$ & $\mathrm{C} 8$ & $29-43$ & SSNTRVLNELNYDNA \\
\hline & & C9 & $33-47$ & RVLNELNYDNAGTNL \\
\hline & & $\mathrm{C} 10$ & $37-51$ & ELNYDNAGTNLYNEL \\
\hline & & C11 & $41-55$ & DNAGTNLYNELEMNY \\
\hline & & $\mathrm{C} 12$ & $45-59$ & TNLYNELEMNYYGKQ \\
\hline & & $\mathrm{C} 13$ & $49-63$ & NELEMNYYGKQENWY \\
\hline & & C14 & $53-67$ & MNYYGKQENWYSLKK \\
\hline & & C15 & $57-71$ & GKQENWYSLKKNSRS \\
\hline \multirow[t]{3}{*}{ Cp6 } & $309-331$ & C46 & $309-323$ & EEPSDKHIKEYLNKI \\
\hline & & $\mathrm{C} 47$ & $313-327$ & DKHIKEYLNKIQNSL \\
\hline & & $\mathrm{C} 48$ & $317-331$ & KEYLNKIQNSLSTEW \\
\hline \multirow[t]{8}{*}{ Cp9 } & $357-397$ & $\mathrm{C} 58$ & $357-371$ & ELDYANDIEKKICKM \\
\hline & & C59 & $361-375$ & ANDIEKKICKMEKCS \\
\hline & & $\mathrm{C} 60$ & $365-379$ & EKKICKMEKCSSVFN \\
\hline & & C61 & $369-383$ & CKMEKCSSVFNWNS \\
\hline & & C62 & $373-387$ & KCSSVFNWNSSIGL \\
\hline & & C63 & $377-391$ & VFNWNSSIGLIMVL \\
\hline & & C64 & 381-395 & VNSSIGLIMVLSFLF \\
\hline & & C65 & $383-397$ & SSIGLIMVLSFLFLN \\
\hline
\end{tabular}

Four CSP peptide pools, Cp1, Cp2, Cp6, and Cp9 were selected as they elicited the highest responses overall in ELISpot assays with Ad-CA-immunized volunteers (see reference 7 and Figure 3).

peptides in $100 \mu \mathrm{L}$ of complete medium at a final concentration of $10 \mu \mathrm{g} / \mathrm{mL}$ of each peptide tested [41]. Cultures were incubated for 36 hours at $37^{\circ} \mathrm{C}, 5 \% \mathrm{CO} 2$. Each PBMC sample was assayed in duplicate, triplicate, or quadruplicate and the number of IFN- $\gamma$-secreting spot forming cells (sfc) was counted using an automated ELISpot reader (AID, GmbH, Germany). The positive control was commercially obtained Class I Peptide Pool Plus (CEF; Anaspec, USA) that stimulates IFN- $\gamma$ from CD8+ T cells [42]. Negative control was media with all supplements except antigen-specific stimulants. In duplicate assays, both values were used in the analysis. For triplicate or quadruplicate assays, outliers were rejected if any single value contributed more than $50 \%$ of the standard deviation of the replicates and if its value was three-fold greater or three-fold less than the average of the remaining two (or three) values. The mean number of sfc obtained in negative control wells was subtracted from the value of each test well from the same sample. Negative counts generated by this background subtraction were converted to zero. The mean number of spots of the test sample was then calculated and expressed as $\mathrm{sfc} / \mathrm{million}(\mathrm{sfc} / \mathrm{m})$. A positive response was defined as a significant difference $(\mathrm{p}=<0.05)$ between the average of sfc in test wells and negative control wells (Student's two tailed $t$-test), plus at least a doubling of sfc in test wells relative to negative control wells, plus a difference of at least $10 \mathrm{sfc}$ between test and negative control wells [7].

\section{Characterization of ELISpot IFN- $\gamma$-producing cells by T-cell subset depletions}

PBMC were depleted of T-cell subsets using anti-human CD4+ or anti-CD8+ coated Dynabeads M-450 (Dynal, Great Neck, NY, USA) following the manufacturer's instructions as previously described [7]. Mock depletion was done with Dynabeads coated with sheep anti-mouse IgG. Flow cytometry confirmed that T-cell subset depletions were $>99 \%$ in all experiments. Data are presented as $\mathrm{sfc} / \mathrm{m}$ and per cent decrease or increase in activity after depletion.

\section{Intracellular cytokine staining (ICS)}

ICS was performed as published previously [14]. Cryopreserved PBMC were thawed, washed, and resuspended at $1 \times 10^{6}$ cells per $\mathrm{mL}$ in complete medium. Peptides were used at $10 \mu \mathrm{g} / \mathrm{mL}$ and costimulatory antibodies anti-CD28 and anti-CD4 + 9d (BD Bioscience, San Jose, CA, USA) were used at $1 \mu \mathrm{g} / \mathrm{mL}$. Stimulants were added to cells and incubated at $37^{\circ} \mathrm{C}$ with $5 \% \mathrm{CO}_{2}$ for two hours. Cells were stained with anti-CD3, anti-CD4+, anti-CD8+, anti-IFN- $\gamma$, anti-TNF $\alpha$, and anti-IL2 and the entire available sample was acquired on a BD LSRII using FACSDiVa (BD Bioscience) software. Data were analysed using FlowJo software (Treestar, Inc). The gating strategy involved progressively measuring total cells; viable cells; lymphocytes; T cells; CD4+ or CD8+ populations; and finally a specific cell type expressing a specific cytokine. Results were transferred to Prism (GraphPad) for graphing and data were corrected for media responses. A positive response was greater than the medium controls + three standard deviations $(0.03 \%)$.

\section{NetMHC-based epitope predictions}

NetMHC [13] was used to predict the MHC class 1 binding affinities, expressed as the half maximum inhibitory concentration $\left(\mathrm{IC}_{50}\right)$ of minimal 8-10mer epitopes within the 15mers that matched the HLA alleles expressed by the volunteers used in each assay. Peptides with predicted $\mathrm{IC}_{50}$ binding affinities less than $500 \mathrm{nM}$ were considered strong binders, those 500-5,000 $\mathrm{nM}$ were considered weak binders, and those $>5,000 \mathrm{nM}$ was considered nonbinders [43]. 


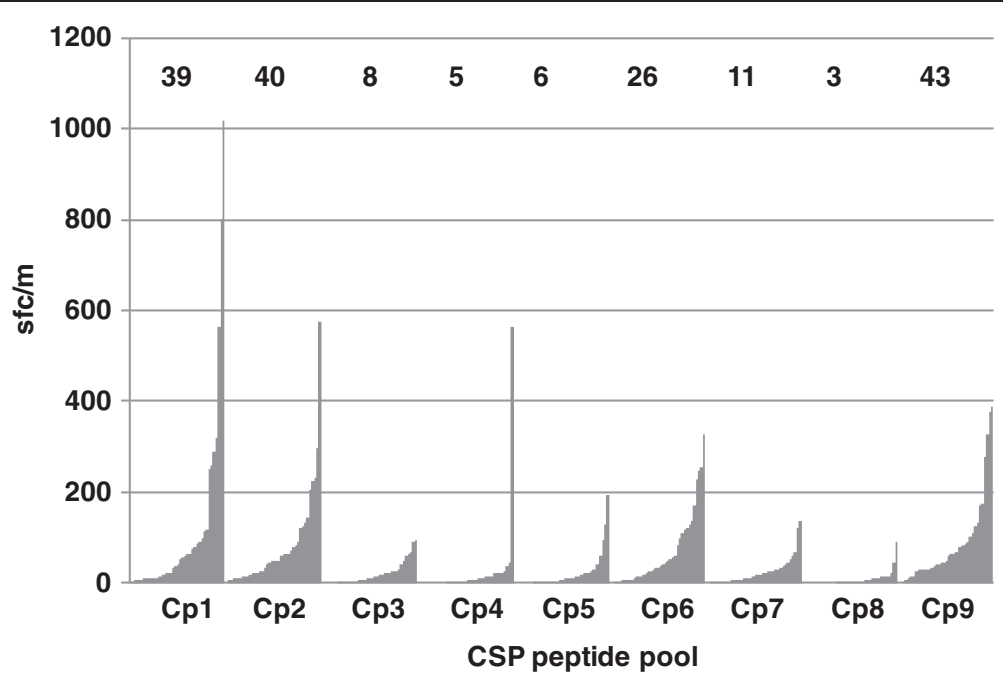

Figure 3 ELISpot activity of CSP peptide pools with all volunteers in adenovirus-vectored CSP trials. The ELISpot activities of all subjects from three adenovirus-vectored CSP trials (see Figure 2) recalled by each CSP peptide pool (Cp1-Cp9) were arranged in ascending order of activity. The numbers above each peptide pool are the geometric means of activities to that pool. Cp1, Cp2, Cp6 and Cp9 were selected for this study as the immunodominant pools.

\section{Results}

\section{Volunteers}

A total of 17 immunized volunteers were used in all experiments (Table 1): five of six volunteers immunized with Ad-CA in trial 1 [7]; three of 18 volunteers immunized with Ad-CA in trial 2 ([9] and nine of 11 volunteers immunized with Ad-C in trial 3 (Table 1). These volunteers expressed a total of 17 different HLA A allele groups representing all HLA A supertypes [33,44] and 17 HLA B allele groups representing all HLA B supertypes (Table 1).

\section{ELISpot activity of CSP 15mers with volunteers immunized with Ad-C or Ad-CA}

The hypothesis was that NetMHC would predict minimal binding epitopes (affinity $<5,000 \mathrm{nM}$ ) in individual 15mers positive in ELISpot assay that were restricted by HLA allele groups that matched the HLA expressed by each volunteer. Each of the 26 15mers within each of the four dominant pools (Table 2) was used as a stimulant in individual ELISpot assays conducted using PBMC from five volunteers immunized with Ad-CA (v01, v02, v05, v08 and v12) (no CHMI trial) and five volunteers immunized with Ad-C (v41, v49, v58, v61 and v69). No volunteers from the Ad-CA with CHMI trial had sufficient PBMC to be included. All results are shown in Additional file 1 and the positive results are shown in Table 3.

Fifteen of the 26 tested 15mers were positive by ELISpot assay (Table 3). Although responses varied, it appeared that the inclusion of the AMA1 in the Ad-CA vaccine did not interfere with CSP epitope recognition by PBMC. As previously seen with NetMHC predictions [33], about $25 \%$ of the 15mers containing putative HLA-matched epitopes with predicted IC50's $<5,000 \mathrm{nM}$ gave positive responses (see Additional file 1). No 15mer containing a predicted epitope was positive with all HLA-matched volunteers, and no volunteer was always positive with all 15mers containing predicted HLA-matched epitopes. When the activity of each positive $15 \mathrm{mer}$ was calculated as a per cent of the parent pool activity, these varied from $25-297 \%$, with percentages $<100 \%$ suggesting that the parent pool may contain other 15 mers able to recall responses, and percentages $>100 \%$ suggesting that the various 15 mers in the parent pool may not have been fully processed and presented.

\section{NetMHC prediction of class I-restricted epitopes within CSP 15 mer peptides}

NetMHC predicted 17 HLA-matched minimal epitopes from the fifteen positive 15mers active in the ELISpot assay (Table 4), of which 11 were predicted to be strong binders $\left(\mathrm{IC}_{50}<500 \mathrm{nM}\right)$ and five were predicted to be weak binders $\left(\mathrm{IC}_{50} 500-5,000 \mathrm{nM}\right)$. NetMHC identified one epitope (E5) where the $\mathrm{IC}_{50}(>5,000 \mathrm{nM})$ was too low to confirm class I binding $(>5,000 \mathrm{nM})$. The predicted putative epitopes were numbered E1-E17 in sequence from the $\mathrm{N}$-terminal end of CSP. The predicted epitopes included seven 9mers (E2, E6, E7, E8, E10, E12, E13) and ten 10mers (E1, E3, E4, E5, E9, E11, E14, E15, E16, E17). Eleven predicted epitopes were from the Nterminal region (E1 to E11) and six epitopes were from the C-terminal region (E12 to E17). Potential putative epitopes located in regions of the CSP not covered by the four dominant pools (see Figure 1) were not considered in this study. 
Table 3 ELISpot IFN- $\gamma$ activity of CSP peptide pools and individual 15-mer peptides within these pools

\begin{tabular}{|c|c|c|c|c|c|c|c|c|}
\hline Pool & Vol. & Vaccine & 15mer peptide & AA no. & Sequence & Pool sfc/m & $15 \mathrm{mer} \mathrm{sfc} / \mathrm{m}$ & Percent of pool \\
\hline Cp1 & 58 & $\mathrm{Ad}-\mathrm{C}$ & $\mathrm{C} 3$ & $9-23$ & SVSSFLFVEALFQEY & 116 & 29 & 25.0 \\
\hline Cp1 & 05 & $\mathrm{Ad}-\mathrm{CA}$ & $\mathrm{C3}$ & & SVSSFLFVEALFQEY & 142 & 65 & 45.8 \\
\hline Cp1 & 69 & $\mathrm{Ad}-\mathrm{C}$ & C3 & & SVSSFLFVEALFQEY & 411 & 385 & 93.7 \\
\hline Cp1 & 12 & $\mathrm{Ad}-\mathrm{CA}$ & C4 & $13-27$ & FLFVEALFQEYQCYG & 64 & 87 & 135 \\
\hline Cp1 & 05 & $\mathrm{Ad}-\mathrm{CA}$ & C4 & & FLFVEALFQEYQCYG & 142 & 44 & 31.0 \\
\hline Cp1 & 01 & $\mathrm{Ad}-\mathrm{CA}$ & C4 & & FLFVEALFQEYQCYG & 77 & 48 & 62.3 \\
\hline Cp1 & 69 & $\mathrm{Ad}-\mathrm{C}$ & C4 & & FLFVEALFQEYQCYG & 411 & 368 & 89.5 \\
\hline Cp1 & 58 & $\mathrm{Ad}-\mathrm{C}$ & $\mathrm{C} 5$ & $17-31$ & EALFQEYQCYGSSSN & 116 & 105 & 90.5 \\
\hline Cp1 & 58 & $\mathrm{Ad}-\mathrm{C}$ & C6 & $21-35$ & QEYQCYGSSSNTRVL & 116 & 83 & 71.6 \\
\hline Cp2 & 49 & $\mathrm{Ad}-\mathrm{C}$ & C8 & $29-43$ & SSNTRVLNELNYDNA & 64 & 41 & 64.1 \\
\hline Cp2 & 41 & $\mathrm{Ad}-\mathrm{C}$ & $\mathrm{C} 10$ & $37-51$ & ELNYDNAGTNLYNEL & 83 & 35 & 42.2 \\
\hline $\mathrm{Cp} 2$ & 49 & $\mathrm{Ad}-\mathrm{C}$ & $\mathrm{C} 12$ & $45-59$ & TNLYNELEMNYYGKQ & 64 & 28 & 43.8 \\
\hline $\mathrm{Cp} 2$ & 12 & $\mathrm{Ad}-\mathrm{CA}$ & $\mathrm{C} 12$ & & TNLYNELEMNYYGKQ & 331 & 411 & 124 \\
\hline $\mathrm{Cp} 2$ & 01 & $\mathrm{Ad}-\mathrm{CA}$ & $\mathrm{C} 12$ & & TNLYNELEMNYYGKQ & 119 & 119 & 100 \\
\hline $\mathrm{Cp} 2$ & 01 & $\mathrm{Ad}-\mathrm{CA}$ & $\mathrm{C} 13$ & $49-63$ & NELEMNYYGKQENWY & 119 & 116 & 97.5 \\
\hline Cp2 & 12 & $\mathrm{Ad}-\mathrm{CA}$ & $\mathrm{C} 13$ & & NELEMNYYGKQENWY & 331 & 334 & 100 \\
\hline Cp6 & 61 & $\mathrm{Ad}-\mathrm{C}$ & $\mathrm{C} 47$ & $313-327$ & DKHIKEYLNKIQNSL & 53 & 48 & 90.6 \\
\hline Cp6 & 41 & $\mathrm{Ad}-\mathrm{C}$ & $\mathrm{C} 48$ & $317-331$ & KEYLNKIQNSLSTEW & 95 & 103 & 108 \\
\hline Cp6 & 05 & $\mathrm{Ad}-\mathrm{CA}$ & C48 & & KEYLNKIQNSLSTEW & 130 & 106 & 81.5 \\
\hline Cp6 & 58 & $\mathrm{Ad}-\mathrm{C}$ & $\mathrm{C} 48$ & & KEYLNKIQNSLSTEW & 24 & 45 & 187 \\
\hline Cp9 & 61 & $\mathrm{Ad}-\mathrm{C}$ & $\mathrm{C} 60$ & $365-379$ & EKKICKMEKCSSVFN & 128 & 39 & 30.5 \\
\hline Cp9 & 01 & $\mathrm{Ad}-\mathrm{CA}$ & $\mathrm{C} 62$ & $373-387$ & KCSSVFNWNSSIGL & 39 & 116 & 297 \\
\hline Cp9 & 08 & $\mathrm{Ad}-\mathrm{CA}$ & $\mathrm{C} 63$ & $377-391$ & VFNWNSSIGLIMVL & 142 & 109 & 76.8 \\
\hline Cp9 & 08 & $\mathrm{Ad}-\mathrm{CA}$ & C64 & $381-395$ & VNSSIGLIMVLSFLF & 142 & 91 & 64.1 \\
\hline Cp9 & 01 & $\mathrm{Ad}-\mathrm{CA}$ & $\mathrm{C} 65$ & $383-397$ & SSIGLIMVLSFLFLN & 39 & 46 & 117 \\
\hline Cp9 & 02 & $\mathrm{Ad}-\mathrm{CA}$ & $\mathrm{C} 65$ & & SSIGLIMVLSFLFLN & 16 & 44 & 275 \\
\hline Cp9 & 08 & $\mathrm{Ad}-\mathrm{CA}$ & $\mathrm{C} 65$ & & SSIGLIMVLSFLFLN & 142 & 62 & 43.7 \\
\hline
\end{tabular}

All individual 15mer peptides within the CSP peptide pools Cp1, Cp2, Cp6 and Cp9 were tested in ELISpot assay using frozen PBMC collected 28 days after Ad-CA or 19-23 days after Ad-C immunization. 15 individual 15mer peptides of the 2615 mer peptides elicited positive recall responses from at least one volunteer immunized with $\mathrm{Ad}-\mathrm{CA}$ and $\mathrm{Ad}-\mathrm{C}$, and each of the ten volunteers responded positively to at least one $15 \mathrm{mer}$.

HLA promiscuity of predicted epitopes within 15 mers

Two putative epitopes were predicted to be restricted by different HLA supertypes (Table 4): E2 by both A*01:01 allele group (A01 supertype) and $B * 35: 01$ allele group (B07 supertype), and E12 by A*02:01 allele group (A02 supertype) and $B * 08: 01$ allele group (B08 supertype), supporting recent meta-analyses that $>50 \%$ of IEDBlisted epitopes bind two or more HLA molecules [40]. The remaining putative epitopes were predicted to be restricted by single HLA allele groups: E1, E4, E5, E14 and E17 by $A * 02: 01$ (A02 supertype); E3, E9 and E11 by A*30:02 (A01 supertype); E15 and E16 by A*68:02 (A02 supertype); E10 and E13 by B*44:02 (B44 supertype); E6 and E8 by $B * 15: 03$ (B27 supertype); and E7 by B*35:01 (B07 supertype). Epitopes predicted to bind to supertypes A03 and B58, which were expressed by some volunteers (Table 1 ), were not identified by NetMHC in the 15 mers positive in ELISpot from these four selected peptide pools, although this does not mean definitively that none occur.

\section{ELISpot activity of synthesized minimal epitope peptides} with volunteers immunized with $\mathrm{Ad}-\mathrm{CA}$ or $\mathrm{Ad}-\mathrm{C}$

Six volunteers were selected on the basis of HLAmatching and availability of PBMC to test in ELISpot assays five of the predicted putative epitopes identified through the comprehensive 15 mer screen and NetMHC, E1, E2, E3, E14 and E18. These were v58, v69, 37 and $\mathrm{v} 40$ from the Ad-C trial and v127 and v156 from the Ad-CA CHMI trial. The pairing of volunteers and epitopes is shown in the top half of Table 5.

A second round of assays was also conducted (strategy 2) to analyse four additional predicted putative epitopes selected from positive parent 15 mers, numbered E19 to E22. E19 and E20 were predicted to bind to $A * 24: 03$ and 
Table 4 Predicted CD8+ T cell-restricted epitopes specific for each volunteer within CSP 15mer peptides

\begin{tabular}{|c|c|c|c|c|c|c|c|c|}
\hline Pool & $15 \mathrm{mer}$ & Vol. & Predicted epitope & AA no. & $\mathrm{IC}_{50} \mathrm{nM}$ & HLA allele group & HLA supertype & Epitope no. \\
\hline \multirow[t]{8}{*}{ Cp1 } & $\mathrm{C} 3$ & 58 & SVSSFLFVEALFQEY & $13-22$ & 258 & $A^{*} 02: 01$ & $\mathrm{~A} 02$ & E1 \\
\hline & & 05 & SVSSFLFVEALFQEY & $15-23$ & 50 & $A^{*} 01: 01$ & A01 & E2 \\
\hline & & 69 & SVSSFLFVEALFQEY & $15-23$ & 68 & $B * 35: 01$ & B07 & E2 \\
\hline & C4 & 12 & FLFVEALFQEYQCYG & $14-23$ & 226 & $A^{*} 30: 02$ & A01 & E3 \\
\hline & & 01 & $\underline{\text { FLFVEALFQEYQCYG }}$ & $13-22$ & 258 & $A^{*} 02: 01$ & $\mathrm{~A} 02$ & E1 \\
\hline & & 69 & FLFVEALFQEYQCYG & $15-23$ & 68 & $B * 35: 01$ & B07 & E2 \\
\hline & C5 & 58 & EALFQEYQCYGSSSN & $18-27$ & 2174 & $A^{*} 02: 01$ & $\mathrm{~A} 02$ & E4 \\
\hline & C6 & 58 & QEYQCYGSSSNTRVL & $23-32$ & 11714 & $A^{*} 02: 01$ & $\mathrm{~A} 02$ & E5 \\
\hline \multirow[t]{6}{*}{ Cp2 } & $\mathrm{C} 8$ & 49 & SSNTRVLNELNYDNA & $32-40$ & 4075 & $B^{*} 15: 03$ & B27 & E6 \\
\hline & $\mathrm{C} 10$ & 41 & ELNYDNAGTNLYNEL & $40-48$ & 321 & $B^{*} 35: 01$ & B07 & E7 \\
\hline & $\mathrm{C} 12$ & 49 & TNLYNELEMNYYGKQ & $45-53$ & 1087 & $B^{*} 15: 03$ & B27 & E8 \\
\hline & & 12 & TNLYNELEMNYYGKQ & $47-56$ & 25 & $A^{*} 30: 02$ & $\mathrm{~A} 01$ & E9 \\
\hline & & 01 & TNLYNELEMNYYGKQ & $49-57$ & 468 & $B^{*} 44: 02$ & B44 & E10 \\
\hline & $\mathrm{C} 13$ & 12 & NELEMNYYGKQENWY & $54-63$ & 132 & $A^{*} 30: 02$ & A01 & E11 \\
\hline \multirow[t]{4}{*}{ Cp6 } & C47 & 61 & DKHIKEYLNKIQNSL & $319-327$ & 27 & $A^{*} 02: 01$ & $\mathrm{~A} 02$ & E12 \\
\hline & C48 & 41 & KEYLNKIQNSLSTEW & $319-327$ & 27 & $A^{*} 02: 01$ & $\mathrm{~A} 02$ & E12 \\
\hline & & 05 & KEYLNKIQNSLSTEW & $319-327$ & 83 & $B^{*} 08: 01$ & B08 & E12 \\
\hline & & 58 & KEYLNKIQNSLSTEW & $319-327$ & 27 & $A^{*} 02: 01$ & A02 & E12 \\
\hline \multirow[t]{7}{*}{ Cp9 } & $\mathrm{C} 60$ & 61 & EKKICKMEKCSSVFN & $371-379$ & 2353 & $B^{*} 44: 02$ & B44 & E13 \\
\hline & C62 & 01 & KCSSVFNVVNSSIGL & $376-385$ & 470 & $A^{*} 02: 01$ & $\mathrm{~A} 02$ & E14 \\
\hline & C63 & 08 & VFNVVNSSIGLIMVL & $379-388$ & 70 & $A^{*} 68: 02$ & $\mathrm{~A} 02$ & E15 \\
\hline & C64 & 08 & VNSSIGLIMVLSFLF & $382-391$ & 294 & $A^{*} 68: 02$ & $\mathrm{~A} 02$ & E16 \\
\hline & C65 & 01 & SSIGLIMVLSFLFLN & $387-396$ & 53 & $A^{*} 02: 01$ & $\mathrm{~A} 02$ & $\mathrm{E} 17^{*}$ \\
\hline & & 02 & SSIGLIMVLSFLFLN & $387-396$ & 53 & $A^{*} 02: 01$ & $\mathrm{~A} 02$ & $\mathrm{E} 17^{*}$ \\
\hline & & 08 & SSIGLIMVLSFLFLN & $387-396$ & 816 & $A^{*} 02: 01$ & $\mathrm{~A} 02$ & $\mathrm{E} 17^{*}$ \\
\hline
\end{tabular}

The 15 mer peptides that were recognized by the volunteers in the initial screen (Table 2 ) were analysed by NetMHC to predict affinity HLA binding by minimal $\mathrm{CD} 8+\mathrm{T}$ cell epitopes within each 15-mer (underlined and bold). Those minimal epitopes with the strongest binding affinities for the HLA alleles of each volunteer were selected. Each minimal epitope was specific for a known HLA allele within each supertype. Two listings from Table 4 were not included here because the same minimal peptide was predicted for the same volunteer for two overlapping 15mers (v01, C12 and C13; v05, C3 and C4). Nine of these epitopes were synthesized and further screened by ELISpot with HLA-matched volunteers (see Table 5).

*E17, a 10-mer, was predicted to contain a 9mer sequence LIMVLSFLF labelled E18 (see Table 5).

Vol. = volunteer; $A A=$ amino acid; No. = number.

A*02:01, respectively, while E21 was predicted to bind promiscuously to $A * 24: 02, A^{*} 23: 01$ and $A * 29: 02$. Like E19 and E20, E22 was predicted to bind to $A^{*} 02: 01$. PBMC were available from six HLA-matched volunteers to test these four additional peptides, including v156 (AdCA, with CHMI), v37 (AdC) and v40 (AdC), all used to test the first set of epitopes (see above), and three new volunteers, v125 (AdCA, with CHMI), v63 (AdC) and v68 (AdC). The pairing of volunteers and these four additional putative epitopes for the conduct of ELISpot assays is shown in the bottom half of Table 5 .

The positive control for each assay was the parent CSP peptide pool that contained the 15 mer peptide from which these epitopes were derived (noting that the magnitude of response recalled by some parent pools was lower than that recalled by predicted epitope it contained). We also conducted six assays where the volunteer and epitope matched at the supertype but not the allele group level, and also seven assays constituting HLA mismatches.

Altogether thirty-five assays were conducted using the nine synthesized epitopes, with the positive assay results shown in Table 5, ranging from 0 to $331 \mathrm{sfc} / 10^{6} \mathrm{PBMC}$ (for all results, see Additional file 2). When the activity of each positive result was calculated as a per cent of the parent pool activity, these varied from 35.4 - 674\%, suggesting that the parent pool may contain other epitopes that were not tested here $(<100 \%)$, or that the various epitopes in the parent pool may not have been fully processed and presented (>100\%). Interestingly, nearly all assays (18/20) matching synthesized minimal epitopes to research subjects by allele group were positive. The two exceptions were E19 that matched v40 and E22 that 
Table 5 ELISpot IFN-ץ activity of CSP peptide pools and predicted 8-10mer epitopes within these pools (strategy 1 and strategy 2)

\begin{tabular}{|c|c|c|c|c|c|c|c|c|c|c|}
\hline Pool & Vol. & Epitope no. & $\begin{array}{l}\text { Epitope } \\
\text { sequence }\end{array}$ & AA no. & HLA allele group & HLA supertype & $\mathrm{IC}_{50} \mathrm{nM}$ & Pool sfc/m & Epitope $s f c / m$ & Percent of pool \\
\hline$\overline{C p 1}$ & $58^{1}$ & E1 & FLFVEALFQE & $13-22$ & $A^{*} 02: 01$ & $\mathrm{~A} 02$ & 258 & ND & 49 & \\
\hline \multirow[t]{2}{*}{ Cp1 } & $156^{3}$ & E1 & $\underline{\text { FLFVEALFQE }}$ & $13-21$ & $A^{*} 29: 02$ & A01A24 & 422 & 126 & 105 & 83.3 \\
\hline & & E1 & $\underline{\text { FLFVEALFQE }}$ & $13-20$ & $A^{*} 29: 02$ & $\mathrm{~A} 01 \mathrm{~A} 24$ & 109 & & & \\
\hline Cp1 & $69^{2}$ & E2 & FVEALFQEY & $15-23$ & $B * 35: 01$ & B07 & 68 & 399 & 268 & 67.2 \\
\hline Cp1 & $127^{3}$ & E2 & FVEALFQEY & $15-23$ & $A^{*} 01: 01$ & A01 & 63 & 69 & 89 & 129 \\
\hline Cp1 & $69^{2}$ & E3 & LFVEALFQEY & $14-23$ & $A * 30: 02$ & $\mathrm{~A} 01$ & 63 & ND & 259 & \\
\hline Cp1 & $69^{2}$ & E3 (E2) & LFVEALFQEY & $15-23$ & $B * 35: 01$ & B07 & 68 & 399 & 259 & 64.9 \\
\hline Cp1 & $127^{3}$ & E3 (E2) & LFVEALFQEY & $15-23$ & $A^{*} 01: 01$ & $\mathrm{~A} 01$ & 63 & 69 & 99 & 144 \\
\hline Cp9 & $37^{1}$ & E14 & SVFNVNSSI & $376-385$ & $A^{* 68: 02}$ & $\mathrm{~A} 02$ & 18 & 79 & 28 & 35.4 \\
\hline Cp9 & $58^{1}$ & E14 & SVFNWNSSI & $376-385$ & $A^{*} 02: 01$ & $\mathrm{~A} 02$ & 470 & 13 & 80 & 615 \\
\hline Cp9 & $40^{1}$ & E14 & SVFNWNSSI & $377-385$ & $A^{*} 23: 01$ & $\mathrm{~A} 24$ & 1801 & $43^{4}$ & 104,72 & 242,167 \\
\hline Cp9 & $156^{3}$ & E18 & LIMVLSFLF & $387-395$ & $A^{*} 29: 02$ & A01A24 & 190 & 64 & 156 & 244 \\
\hline Cp9 & $37^{1,2}$ & E18 & LIMVLSFLF & $387-395$ & $B^{* 15: 03}$ & B27 & 111 & $79^{4}$ & 55,38 & $69.6,48.1$ \\
\hline $\mathrm{Cp} 9$ & $40^{1}$ & E18 & LIMVLSFLF & $387-395$ & $A^{*} 23: 01$ & A24 & 282 & $43^{4}$ & 290,166 & 674,386 \\
\hline Cp1 & $63^{1}$ & E19 & AlLSVSSFLF & $6-15$ & $A^{*} 24: 03$ & A24 & 1088 & ND & 41 & \\
\hline Cp1 & $125^{3}$ & E20 & SVSSFLFVEA & $9-18$ & $A^{*} 02: 01$ & $\mathrm{~A} 02$ & 25 & 27 & 33 & 122 \\
\hline Cp1 & $68^{1}$ & E21 & SFLFVEALF & $12-20$ & $A^{*} 24: 02$ & A24 & 104 & ND & 34 & \\
\hline Cp1 & $37^{1,2}$ & E21 & SFLFVEALF & $12-20$ & $A^{*} 23: 01$ & A24 & 104 & $36^{4}$ & 53,53 & 147,147 \\
\hline Cp1 & $40^{1}$ & E21 & SFLFVEALF & $12-20$ & $A^{*} 23: 01$ & A24 & 104 & $163^{4}$ & 313,197 & 192,121 \\
\hline Cp1 & $156^{3}$ & E21 & SFLFVEALF & $12-20$ & $A^{*} 29: 02$ & A01A24 & 245 & 120 & 240 & 200 \\
\hline Cp9 & $125^{3}$ & E22 & IMVLSFLFL & $388-396$ & $A^{*} 02: 01$ & $\mathrm{~A} 02$ & 59 & 58 & 29 & 50.0 \\
\hline
\end{tabular}

This table includes all 19 epitope-specific responses that were positive among the 35 that were tested. The presence of two results in the epitope response column (second from right) indicates that two separate experiments were performed. E18 is a 9mer sequence predicted by NetMHC within E17 (Table 4) and was synthesized rather than E17 and tested with three volunteers immunized with Ad-CA or Ad-C. Three of the 9mer sequences that are underlined indicate additional class I-restricted sequences predicted by NetMHC contained within E1 and E14 epitopes respectively. E1 was positive with both the volunteer predicted to recognize the full sequence and the volunteer predicted to recognize two nested epitopes. E14 was positive for both the two volunteers predicted to recognize the full sequence and the one volunteer predicted to recognize the nested epitope. A single assay was performed for v69 and E3; however, E3 contains the E2 sequence that is underlined and has a different predicted restriction than E3, so both are listed. E14 contains a predicted $A^{*} 23: 01$-restricted epitope that is underlined.

${ }^{1}$ PBMC from 28 days after first Ad-C immunization; ${ }^{2}$ PBMC from 19 days after second Ad-C immunization; ${ }^{3}$ PBMC from 28 days after Ad-CA immunization; ${ }^{4}$ The response to the peptide pool was not done in the second assay.

ND, Not Done.

matched v37 and were negative. All six of the assays where the epitope matched at the supertype but not the allele group level, and also all seven HLA mismatches, were negative (Additional file 2).

The findings for each of the nine epitopes were as follows:

E1 (FLFVEALFQE): This sequence was supported as an $A^{*}$ 02:01-restricted (A02 supertype) epitope as the synthesized peptide was active with v58 (Table 5). E1 was also positive with v156 who does not express A*02:01; however, E1 contains the 9mer FLFVEALFQ and the 8mer FLFVEALF that NetMHC predicted each bound to $A * 29: 02$ that is expressed by v156 (Table 5). Therefore, E1 is A*02:01-restricted and also contains two predicted sequences restricted by $A * 29: 02$ (both of which are listed in the table).

E2 (FVEALFQEY): This sequence was supported as a B*35:01-restricted epitope (B07 supertype) as the synthesized peptide was active with v69 (Table 5). E2 was also predicted by NetMHC to be an $\mathrm{A}^{*} 01: 01$ restricted epitope (A01 supertype) using v05; however, PBMC were not available from v05 to test the synthesized peptide. E2, however, could be tested with v127, also A*01:01-restricted, and was active. Therefore E2 appears restricted by two allele groups, $B * 35: 01$ and A*01:01 that belong to different supertypes, B07 and A01, respectively.

E3 (LFVEALFQEY): This sequence was initially identified as $A * 30: 02-$ restricted, as the parent C4 15mer 
was active with v12 (Table 4). Since there were not sufficient PBMC from v12, E3 was tested and was active with v69, concordant with NetMHC-predicted binding to $A * 30: 02$ (A01 supertype). E3 contains the 9mer E2 sequence (FVEALFQEY) that NetMHC predicted binds to $B * 35: 01$ that is also expressed by v69 (see E2 above). Both potential HLA associations ( $A * 30: 02, B * 35: 01)$ for v69's positive result ( $259 \mathrm{sfc} / \mathrm{m})$ are listed in Table 5. E3 was also positive with v127, concordant with the NetMHC prediction that the E2 sequence within E3 bound to A*01:01 (see E2 above). Therefore, activities of E3 with v127 and v69 are similar to those of E2, with the same allele group restrictions, $B * 35: 01$ and $A * 01: 01$ (B07 and A01 supertypes, respectively).

E14 (SVFNVVNSSI): This sequence was initially identified as $\mathrm{A}^{*}$ 02:01-restricted as the parent $15 \mathrm{mer}$, C62, was positive with v01 (Table 4). Since there were not sufficient PBMC from v01, it was tested with v58 who shared the same HLA allele, A*02:01 (A02 supertype). E14 was also positive with v37 and NetMHC predicted binding to $A * 68: 02$ that like $A^{*}$ 02:01 is part of the A02 supertype. E14 was also positive with $\mathrm{v} 40$ and NetMHC predicted a $9 \mathrm{mer}$ sequence VFNVVNSSI contained within E14 that is restricted by $A * 23: 01$ (A24 supertype). Therefore we conclude that E14 is restricted by $A^{*} 02: 01$ and $A^{*} 68: 02$ (both A02 supertype) and contains a sequence that is predicted to be restricted by $A^{*} 23: 01$ (A24 supertype). E18 (LIMVLSFLF): This was positive with v156 and NetMHC predicted this sequence binds to $A * 29: 02$ (A01A24 supertype) that is expressed by v156. E18 was also positive with v37 and NetMHC predicted this sequence also binds to B*15:03 (B27 supertype). Finally, E18 was positive with $\mathrm{v} 40$, and NetMHC predicted binding to A*23:01 (A24 supertype). Therefore, E18 ELISpot activity was restricted by three allele groups, $A * 29: 02, B * 15: 03$ and $A * 23: 01$ that are members of three HLA supertypes, A01A24, B27 and A24, respectively. $\mathrm{E} 17$, which was not synthesized since several other $A^{*}$ 02:01-restricted putative epitopes were tested (E1, E14, E20 and E22), has not yet been confirmed as A*02:01-restricted in ELISpot assays.

E19 (AILSVSSFLF): This sequence was predicted as an $A^{*}$ 23:01 (A24 supertype)-restricted epitope using v40. Since there were not sufficient PBMC from v40, E19 was tested and was positive with v63 who expresses $A^{*} 24: 03$ that is also a member of the A24 supertype. NetMHC predicted that this 10mer was A*24:03-restricted (A24 supertype) with a low binding affinity $\left(\mathrm{IC}_{50} 1088 \mathrm{nM}\right)$. Therefore, it was concluded that E18 may be restricted by $A * 23: 01$ and $A * 24: 03$, both of which are members of the A24 supertype.
E20 (SVSSFLFVEA): This sequence was predicted to be $A^{* 68: 02-r e s t r i c t e d ~(A 02 ~ s u p e r t y p e) ~ u s i n g ~ v 52 . ~ S i n c e ~}$ PBMC were not available from this volunteer, E20 was tested and was active with v125 who does not express A*68:02. However, NetMHC predicted that a $8 \mathrm{mer}$ contained within E20 (SVSSFLFV) is restricted by $\mathrm{A}^{*} 02: 01$ that is expressed by v125 and is also A02 supertype. Therefore E20 may be A*68:02-restricted, but ELISpot assay and NetMHC suggested that it contains a 8mer that is $\mathrm{A}^{*} 02: 01-$ restricted (A02 supertype).

E21 (SFLFVEALF): This sequence was positive with v37; NetMHC predicted binding to A*23:01 (A24 supertype) that is expressed by v37. E21 was also positive with v40 who also expressed the $A * 23: 01$ allele group. In addition, E21 was positive with v156 and NetMHC predicted binding to A*29:02 that is expressed by v156. E21 was also moderately positive with v68; NetMHC predicted binding to $A * 24: 02$ expressed by v68 that like $A * 23: 01$ is a member of the A24 supertype. Therefore, E21 appears to be restricted by $A^{*} 23: 01$ and A*24:02 (both A24) and A*29:02 (A01A24).

E22 (IMVLSFLFL): This sequence gave a modest response against v125 and NetMHC predicted that E22 is $A^{*} 02: 01-$ restricted as $A^{*} 02: 01$ is expressed by v125. In addition, E22 partially overlaps a 10mer

LIMVLSFLFL that is also predicted to be $A^{*} 02: 01$ restricted consistent with v125 expressing the A02 supertype.

\section{Confirmation of class 1-restriction of epitopes using ELISpot depletion and ICS assays}

PBMC from HLA-matched volunteers were available to conduct confirmatory assays for six of the nine predicted minimal epitopes tested: E1, E2, E14, E18, E20 and E21. After CD8+ T cell depletion, ELISpot activities against E1, E2, E18, E21 were reduced by $73 \%-96 \%$ (Table 6) whereas depletion of CD4+ T cells did not affect activity (reduction $<18 \%$ ). For E14, depletion of CD8+ and CD4+ $\mathrm{T}$ cells reduced activity approximately equally (56\% and $50 \%$, respectively). However, CD8+ T cell depletion did not affect activity of E20 whereas CD4+ T cell depletion reduced activity by $78 \%$, suggesting that the response was not CD8+ T cell-dependent. When these epitopes were tested by ICS, results were consistent with the ELISpot depletion studies. CD8+ $\mathrm{T}$ cell interferon-gamma responses were recalled by E1, E2, E14, E18 and E21 at frequencies ranged from $0.12 \%$ (E14) to $0.54 \%$ (E18) of gated CD8+ T cells, similar to the parent pools, except for E20, where the CD8+ T cell frequency was only $0.06 \%$. CD $4+\mathrm{T}$ cell responses were negligible $(\leq 0.04 \%)$. Therefore, five epitopes (E1, E2, E14, E18 and E21) of these six predicted epitopes were confirmed as minimal CD8+ T cell-dependent epitopes, while E20 was not. 


\section{Summary of predicted and confirmed minimal CSP epitopes identified in this study}

The confirmed minimal CSP epitopes are summarized in Table 7. Seventeen 9-10mer epitopes (E1-E17) were initially identified using NetMHC predictions of binding to the HLA A and B alleles expressed by a panel of AdCA and Ad-C-immunized volunteers (Tables 3 and 4). Five of these epitopes were synthesized (E1, E2, E3, E14 and E18) and tested in ELISpot assays. Four of these five epitopes were tested in ELISpot depletion and ICS assays (E1, E2, E14 and E18). Derived from strategy 2, four additional epitopes were synthesized (E19, E20, E21 and E22) and likewise demonstrated activity in ELISpot assays, and two of these were tested in ELISpot depletion and ICS assays (E20, E21). Overall, the restricted availability of PBMC from immunized volunteers allowed only five of these epitopes (E1, E2, E14, E18, and E21) to be confirmed as recalling CD8+ $\mathrm{T}$ cell responses. One additional epitope E20 was tested but could not be confirmed. All 9 of the putative epitopes that were synthesized and studied in ELISpot assays are conserved.

\section{HLA allele promiscuity of identified epitopes using ELISpot assays}

This study could not be extended to many subjects due to limited PBMC samples, but nevertheless supported previous findings that some class I epitopes are sufficiently degenerate to bind to more than one allele group or supertype [24]. As shown in Table 7, E2 was restricted by $A^{*} 01: 01$ (A01 supertype) and B*35:01 (B07 supertype), and E18 was restricted by $\mathrm{A}^{*} 23: 01$ (A24 supertype), $A * 29: 02$ (A01A24 supertype) and B*1503 (B27 supertype). E14 was restricted by two allele groups of the A02 supertype (A*02:01 and $A * 68: 02$ ), and E21 was restricted by two allele groups of the A24 supertype ( $A * 23: 01$ and $A * 24: 02)$ and one allele group of the A01A24 supertype (A*29:02). This promiscuity of restriction is likely underestimated due to the limited availability of PBMC from the 17 volunteers used in this study. When NetMHC was used to predict all restrictions of epitopes within $\mathrm{Cp} 1, \mathrm{Cp} 2, \mathrm{Cp} 6$ and $\mathrm{Cp} 9$, many more potential restrictions were identified that could not be evaluated or verified in this study.

\section{Epitope localization}

Among the 17 predicted putative epitopes, 11 were localized in the N-terminal region, and six were localized to the C-terminal region. Among the nine epitopes that were synthesized and tested in ELISpot assays, six were localized to the N-terminal region (E1, E2, E3, E19, E20, and E21) and three epitopes were localized to the C-terminal regions (E14, E18 and E22). Recently part of the strain 3D7 CSP C-terminal region (aa 310-375) has been crystallized revealing a unique $\alpha$ TSR domain related to other TSR domains that contains a hydrophobic pocket contiguous with the hydrophobic core [45]. Only one of the Cterminal epitopes described here completely lies within the crystallized sequence, E12 (Table 4), which is localized on an outer $\alpha 1$ helix that forms the edge of the hydrophobic pocket, and partially overlaps the Th2R epitope. However, E12 was not tested by itself although the two 15mers containing E12, C47 and C48, were tested in these assays.

Table 6 ELISpot IFN- $\gamma$ activity of CSP predicted epitopes after depletion of CD4+ and CD8+ T cells compared with ICS CD8+ and CD4+ $T$ cell IFN- $\gamma$ activity

\begin{tabular}{|c|c|c|c|c|c|c|c|c|c|}
\hline Vol. & Pool & Epitope no. & Sequence & $\begin{array}{l}\text { HLA allele } \\
\text { group }\end{array}$ & $\begin{array}{l}\text { Control depl. } \\
\mathrm{sfc} / \mathrm{m}\end{array}$ & $\begin{array}{l}\text { CD8+ depl. sfc/m } \\
(\%)^{*}\end{array}$ & $\begin{array}{l}\text { CD4+ depl. sfc/m } \\
(\%)^{*}\end{array}$ & $\begin{array}{l}\mathrm{CD} 8+ \\
\%^{* *}\end{array}$ & $\begin{array}{c}\text { CD4+ } \\
\%^{* *}\end{array}$ \\
\hline \multirow[t]{4}{*}{$\overline{\mathrm{V} 40^{1}}$} & Cp1 & & & & 97 & $5(-95 \%)$ & $82(-15 \%)$ & 0.44 & 0.02 \\
\hline & & E21 & SFLFVEALF & $A^{*} 23: 01$ & 254 & 15 (-94\%) & $226(-11 \%)$ & 0.37 & 0.04 \\
\hline & & E14 & SVFNWNSSI & $A^{*} 23: 01$ & 86 & $38(-56 \%)$ & $43(-50 \%)$ & 0.12 & 0.01 \\
\hline & & E18 & LIMVLSFLF & $A^{*} 23: 01$ & 236 & $23(-90 \%)$ & $210(-11 \%)$ & 0.54 & 0.02 \\
\hline \multirow[t]{2}{*}{$V 69^{2}$} & Cp1 & & & & 445 & $6(-98 \%)$ & $397(-11 \%)$ & 0.53 & 0.01 \\
\hline & & E2 & FVEALFQEY & $B^{*} 35: 01$ & 380 & 17 (-96\%) & $356(-6 \%)$ & 0.48 & 0.00 \\
\hline $\mathrm{V} 125^{3}$ & & E20 & $\underline{\text { SVSSFLFVEA }}$ & $A^{*} 02: 01$ & 79 & 72 (-9\%) & $17(-78 \%)$ & 0.06 & 0.02 \\
\hline \multirow[t]{4}{*}{$V 156^{3}$} & Cp1 & & & & 133 & $0(-100 \%)$ & $135(+2 \%)$ & 0.33 & 0.01 \\
\hline & & E21 & SFLFVEALF & $A^{*} 29: 02$ & 213 & $29(-86 \%)$ & $273(+28 \%)$ & 0.25 & 0.01 \\
\hline & & E1 & $\underline{\text { FLFVEALFQE }}$ & $A^{*} 29: 02$ & 245 & $91(-73 \%)$ & $215(-12 \%)$ & 0.34 & 0.03 \\
\hline & Cp9 & E18 & LIMVLSFLF & $A^{*} 29: 02$ & 307 & $85(-82 \%)$ & $264(-18 \%)$ & 0.26 & 0.01 \\
\hline
\end{tabular}

${ }^{1}$ PBMC from one month after the first Ad-C immunization; ${ }^{2}$ PBMC from 19 days after the second Ad-C immunization; ${ }^{3}$ PBMC from 28 days after challenge following Ad-CA immunization.

*The percent change in ELISpot activity is shown after depletion of CD4+ or CD8+ T cells.

**The percent of CD8+ or CD4+ gated T cells expressing IFN- $\gamma$.

depl. = depletion.

$\mathrm{sfc} / \mathrm{m}=$ spot forming cells/million.

v125 did not have sufficient PBMC to test Cp1. 
Table 7 Summary of predicted and confirmed minimal CSP identified in this study epitopes

\begin{tabular}{|c|c|c|c|c|c|c|c|c|}
\hline $\begin{array}{l}15 \mathrm{mer} \\
\text { peptide }\end{array}$ & $\begin{array}{l}\text { Epitope } \\
\text { number }\end{array}$ & Sequence & AA no. & $\begin{array}{l}\text { 15mer ELISpot } \\
\text { activity }\end{array}$ & $\begin{array}{l}\text { Epitope ELISpot } \\
\text { activity }\end{array}$ & Depl. /ICS & $\begin{array}{l}\text { HLA allele } \\
\text { group }\end{array}$ & $\begin{array}{l}\text { HLA } \\
\text { supertype }\end{array}$ \\
\hline \multirow[t]{5}{*}{ Cp1-C3 } & E1 & FLFVEALFQE & $13-22$ & + & + & + & $A^{*} 02: 01$ & $\mathrm{~A} 02$ \\
\hline & & FLFVEALFQE & $13-21$ & & & & $A^{*} 29: 02$ & $\mathrm{~A} 01 \mathrm{~A} 24$ \\
\hline & & $\underline{\text { FLFVEALFQE }}$ & $13-20$ & & & & $A^{*} 29: 02$ & $\mathrm{~A} 01 \mathrm{~A} 24$ \\
\hline & E2 & FVEALFQEY & $15-23$ & + & + & ND & $A^{*} 01: 01$ & $\mathrm{~A} 01$ \\
\hline & & FVEALFQEY & $15-23$ & + & + & + & $B^{*} 35: 01$ & B07 \\
\hline Cp1-C4 & E3 & LFVEALFQEY & $14-23$ & + & + & ND & $A^{*} 30: 02$ & $\mathrm{~A} 01$ \\
\hline \multirow[t]{3}{*}{ Cp9-C62 } & E14 & SVFNWNSSI & $376-385$ & + & + & ND & $A^{*} 02: 01$ & $\mathrm{~A} 02$ \\
\hline & & & & & + & & $A^{*} 68: 02$ & $\mathrm{~A} 02$ \\
\hline & & SVFNWNSSI & $377-385$ & & + & + & $A^{*} 23: 01$ & A24 \\
\hline \multirow[t]{4}{*}{ Cp9-C65 } & E18 & LIMVLSFLF & $387-395$ & & + & + & $A^{*} 23: 01$ & A24 \\
\hline & & & & & + & + & $A^{*} 29: 02$ & $\mathrm{~A} 01 \mathrm{~A} 24$ \\
\hline & & & & & + & & $B^{*} 15: 03$ & B27 \\
\hline & & & & & & ND & & \\
\hline \multirow[t]{2}{*}{$\mathrm{Cp} 1-\mathrm{Cl}$} & E19 & AILSVSSFLF & $6-15$ & & + & ND & $A^{*} 24: 03$ & A24 \\
\hline & & & & & & & $A^{*} 23: 01$ & A24 \\
\hline Cp1-C2 & E20 & $\underline{\text { SVSSFLFVEA }}$ & $9-18$ & & + & $(+)$ & $A^{*} 02: 01$ & $\mathrm{~A} 02$ \\
\hline \multirow[t]{3}{*}{ Cp1-C3 } & E21 & SFLFVEALF & $12-20$ & & + & + & $A^{*} 23: 01$ & A24 \\
\hline & & & & & + & + & $A^{*} 29: 02$ & $\mathrm{~A} 01 \mathrm{~A} 24$ \\
\hline & & & & & + & ND & $A^{*} 24: 02$ & A24 \\
\hline Cp9-C65 & $\mathrm{E} 22$ & IMVLSFLFL & $388-396$ & & + & ND & $A^{*} 02: 01$ & $\mathrm{~A} 02$ \\
\hline
\end{tabular}

$+=$ Positive activity of the $15 \mathrm{mer}$ and predicted epitope in ELISpot assay, or recall of CD8+ T cells in ELISpot depletion (Depl.) assay or intracellular staining/flow cytometry (ICS) assay. (+) = Result not conclusive.

Underlined sequences indicate NetMHC-predicted putative class I-restricted epitopes within E1, E14 and E20.

The five epitopes with + in the Depl./ICS column are confirmed as CD8+ dependent.

Predicted and not confirmed E15, E16 and E17 and confirmed E14, E18 and E22 localize to a short stretch (aa 376-396) that also contains the GPI anchor leading to the CSP C-terminus [45].

\section{Summary of functional epitopes within Plasmodium falciparum CSP}

The summary of these newly identified epitopes, as well as those previously identified, is shown in Figure 1. Cp1, Cp2, Cp6 and Cp9 contain seven, eight, three and eight 15mer peptides, respectively, that overlap previously described $A * 02: 01-$ restricted epitopes as shown in Figure 1. C1 overlaps D4 and C2 overlaps D3 but neither 15 mer was positive by our criteria with volunteers expressing $A^{*} 02: 01$ (see Additional file 1). C65 overlaps D2, and this $15 \mathrm{mer}$ was positive with v01 and v02 which do express $A^{*} 02: 01$, and we identified an $A^{*}$ 02:01-restricted epitope, E17, that overlaps D2, but E17 was not synthesized and tested in ELISpot assays. C47 and C48 overlap D5 that is $\mathrm{A}^{* 02: 01-r e s t r i c t e d}$ and both were positive in ELISpot assays with volunteers expressing $A^{*} 02: 01$ (v61, v41, and v58, Table 4) and the NetMHC-predicted epitope, E12, is the same as D5. However, NetMHC also predicted E12/D5 to be B*08:01- restricted but E12 was not tested in the ELISpot assay with volunteers expressing $A^{*}$ 02:01 or $B^{*} 08: 01$.

\section{Discussion}

Adenovirus-vectored vaccines (Ad-C and Ad-CA) are being developed to induce the $\mathrm{CD} 8+\mathrm{T}$ cell responses thought to be required for protection against liver stage malaria [7]. The aim of this study was to better understand the cell-mediated immune responses targeting CSP elicited by these vaccines by mapping MHC class I restricted epitopes. The long-term goal was to aid the development of a broadly protective malaria vaccine for genetically diverse populations. To date, only a few class I-restricted epitopes have been described for CSP [24,27,46,47] and these earlier observations have now been extended by identifying additional class I-restricted epitopes.

As a first step, the computer algorithm NetMHC [48] was used to predict 11 putative minimal class 1 restricted epitopes within 15 mer CSP peptides that were active in ELISpot assays conducted using PBMC from research volunteers immunized with the Ad-C- and AdCA-malaria vaccines. Although most HLA-restricted peptides have binding affinities of less than $50 \mathrm{nM}$, 
some may bind in the 50-500 $\mathrm{nM}$ range [43]. Therefore we focused on putative epitopes with predicted binding affinities of less than $500 \mathrm{nM}$. One of these epitopes, E12, has been previously described as D5 (Figure 1) specific for HLA A*02:02, although it was also predicted to bind to HLA B*08:01 in the studies reported here.

While peptide binding to class I MHC molecules is required for $\mathrm{T}$ cell recognition, many peptides that bind with high affinity are not recognized by $\mathrm{T}$ cells [33]. Therefore, it was necessary to demonstrate that these predicted epitopes were recognized by $\mathrm{CD} 8+\mathrm{T}$ cells from $\mathrm{Ad}-\mathrm{C}$ and Ad-CA-immunized volunteers. Five of the predicted epitopes were synthesized and tested with PBMCs from volunteers from the same clinical trials, and all were active as predicted with at least one HLAmatched volunteer. As a second approach, the direct prediction of putative class 1-restricted epitopes was pursued within parent pools that gave robust responses with selected volunteers without first screening individual 15 mers in the ELISpot assay. Four of these epitopes were synthesized and tested, and again, all were active when tested with PBMC from HLA-matched volunteers. Thus NetMHC proved to be a valuable tool to predict epitopes within the parent pool to which the volunteers strongly responded with or without a preliminary screen of individual 15mers. Altogether, 18/20 matched epitope/volunteer pairings used to test the nine synthesized 9-10mers were positive on ELISpot assay. None of these nine putative epitopes has been previously described and all are therefore novel [49]. Having to rely on PBMC that were available meant that the evaluation could not be comprehensive, and indeed many more epitopes were predicted than could be tested.

It was possible to further test six of the nine synthesized epitopes by conducting additional ELISpot assays following $\mathrm{CD} 4+$ or $\mathrm{CD} 8+\mathrm{T}$ cell depletion, and by conducting flow cytometry to phenotype the lymphocytes. Of the six epitopes tested, five demonstrated CD8+ T cell-dependent recall responses. These five also demonstrated a predominant $\mathrm{CD} 8+\mathrm{T}$ cell response on flow cytometry. The fact that most class I-binding peptides are eight to 10 amino acids, while class II peptides range from 12 to 24 residues $[24,50]$, supports the likelihood that the novel epitopes are class I-restricted.

Although testing of previously defined epitopes was not done, some 15 mers tested contained previously identified epitopes. As one example, ELISpot activity was not demonstrated using two 15mers that overlap known $A * 02: 01-$ restricted epitopes: $\mathrm{C} 1$ which overlaps $\mathrm{D} 4$, and $\mathrm{C} 2$ which overlaps D3. The reason for the lack of recall responses to these 15 mers is unclear but probably it was not due to a false prediction by NetMHC, since comparative studies using NetMHC and other predictive algorithms found NetMHC to be the best performer across all HLA molecules, and particularly for predicting epitopes binding to $A * 02: 01$ molecules [51]. D4 and D3 were originally identified using PBMC from individuals living in a malaria-endemic area and therefore are recognized by naturally acquired immune CD8+ $\mathrm{T}$ cells, whereas in this study the Ad-C or Ad-CA vaccines may not induce the same responses as natural transmission. The lack of induced response might also have related to the fact that D4 and D3 lie within the signal sequence of CSP (aa 1-18, Figure 1) that may be cleaved during adenovirus expression of CSP in human cells and not efficiently processed and presented. A second example is provided by the C65 15 mer that contains D2, which was also identified in individuals from malaria-endemic areas. In this case, unlike $\mathrm{C} 1$ and $\mathrm{C} 2$, C65 was positive in the ELISpot assay. This could reflect recognition of D2, or could also reflect other HLA-matched epitopes that were present in C65. Since D2, D3 and D4 were not tested as minimal epitopes, it was not possible to confirm whether a response mimicking naturally-acquired immunity, which responds to these epitopes, was induced by Ad-C or Ad-CA immunization. Future studies are planned to determine whether the novel epitopes identified in this study are also recognized by naturally-exposed individuals.

Of interest is that the RTS,S vaccine contains six previously described class I-restricted epitopes (D7, D1, D5, D6, D9 and D2) as well as three novel class I-restricted epitopes described here (E14, E18 and E22), yet, except for one observation [2], CD8 $+\mathrm{T}$ cell responses have not been described in RTS,S clinical trials [1]. The reasons for the lack of RTS,S-induced CD8+ T cell responses remain unclear but may be related to antigen presentation and processing of a protein-based vaccine as opposed to gene-based vaccines or may reflect the type of stimulants, such as the long synthetic peptides or recombinant proteins used to recall $\mathrm{T}$-cell responses in some of the RTS,S immunological studies.

Earlier analyses of $P$. falciparum epitopes including CSP have suggested a high degree of degeneracy such that minimal 8-10mer peptides bind to more than one HLA allele within different supertypes [24]. This is consistent with findings that many different HLA alleles overlap in their peptide-binding properties [24,3133,52-54]. Further examples were found in our study when NetMHC predictions of the HLA-restrictions of peptides spanning the full length of CSP were analysed (data not shown) suggesting that this HLA supertype promiscuity may be extensive. Promiscuous class Irestricted epitopes that recognize different HLA supertypes have been reported for viral diseases suggesting that many epitopes can be presented on different HLA alleles [38,39], with certain allele pairs frequently sharing epitopes [39]. In this study, the small number of epitopes formally tested precluded a 
comprehensive analysis. Nevertheless, the finding of degeneracy in the peptides that were studied provides encouraging evidence that a CSP adenovirus-vectored vaccine may be immunogenic in genetically diverse populations.

Broad applicability of the vaccine is supported by the lack of sequence variation observed in malaria-endemic areas for most of these epitopes, including all 9 that were synthesized $[16,55,56]$. Amino acid polymorphism may be associated with surface accessibility or immune pressure $[56,57]$. A large study involving isolates from Kenya, India, Cameroon and Venezuela identified only five polymorphic residues in the $\mathrm{N}$-terminus of CSP [16,55]; one of these, a threonine, occurs in the E6 epitope described here. However, an analysis of the sequence of 3D7 CSP compared with nine other strains indicated that aa 1-63 containing E1-E11 as well as aa 371-396 containing E13-E22 are conserved, with only aa 324, 325 and 327, located within E12, showing variability. More frequent polymorphisms are found within the Th2R and Th3R epitopes, which do not overlap the epitopes described in this study $[16,55,56]$. More investigations are needed to determine the extent of polymorphism in class I-restricted epitopes, for example by comparison of sequenced genomes of strain 3D7 with endemic isolates using new technologies [58] that focus on CSP T cell epitopes [59].

Recent studies have suggested that the $\mathrm{N}$-terminal region of CSP folds over and protects the C-terminal region, exposing the $\mathrm{N}$-terminal and repeat regions [4]. CSP peptide pools containing peptides spanning the Nterminus recalled strong CD8+ T cell responses in Ad-C and Ad-CA-immunized volunteers. However, CSP peptide pools containing peptides spanning the C-terminal region recalled $\mathrm{CD} 8+\mathrm{T}$ cell responses of similar magnitude, indicating that immune recognition is not related to localization within the protein sequence as found for other pathogens such as hepatitis C, HIV and influenza viruses [60]. Part of the $\mathrm{N}$-terminal region containing E1, E2, E3, E19, E20 and E21 is proteolytically cleaved during sporozoite invasion, while truncated CSP containing E14, E18 and E22 is carried into the hepatocyte $[4,45,61]$, suggesting that $\mathrm{N}$ - and C-terminal epitopes may be processed and presented to the immune system by different mechanisms. The epitopes identified here are contained within four immunodominant CSP peptide pools, and it is possible that immunodominance is influenced by differences in antigen processing [62].

\section{Conclusions}

This study identified nine putative, conserved minimal epitopes of which five were confirmed as recalling CD8+ $\mathrm{T}$ cell responses. These are restricted by four HLA-A and two HLA-B supertypes that together are expressed by $99.5 \%$ of Caucasians and $98.1 \%$ African Americans [31]. Several of the CSP class I epitopes were found to be degenerate, recognized by multiple HLA alleles, consistent with prior reports [24]. Therefore it is likely that these adenovectored CSP vaccines will elicit CD8+ T cell responses in most Caucasian and African populations.

\section{Additional files}

\section{Additional file 1: ELISpot IFN- $\gamma$ activity of CSP peptide pools and} individual 15-mer peptides within these pools with Ad-CA and Ad-C-immunized volunteers (Strategy 1).

Additional file 2: ELISpot IFN- $\gamma$ activity of synthesized predicted putative epitopes with $\mathrm{Ad}-\mathrm{CA}$ and $\mathrm{Ad}-\mathrm{C}$-immunized volunteers (Strategies 1 and 2).

\section{Competing interests}

DLD is an inventor listed on US Patent No., U.S. Patent No. 2009-0148477 A1, and international patent application PCT/ US06/33982, titled "Adenoviral Vector-based Malaria Vaccines"; TLR and DLD are inventors listed on US Patent Application 12/522,335, and international patent application PCT/ US08/50565 titled "Adenoviral Vector-based Malaria Vaccines".

\section{Authors' contributions}

MS designed research; MS, HG, JL, EA, GB, and MB performed ELISpot assays; FF, JH, and SM performed the ICS assays; YK, BP and AS used NetMHC to predict epitopes; TLR, EV, DLD, CD and LS provided intellectual input. CT was an investigator in the clinical trial; MS, YK, BP, DLD, EV, MRH and TLR wrote the paper. All authors read and approved the final manuscript.

\section{Acknowledgments}

$C T, E V$, and TLR were active duty military personnel at the time they contributed to this work; MS is a US Government employee. The work of these individuals was prepared as part of official government duties. Title 17 USC $\$ 105$ provides that 'Copyright protection under this title is not available for any work of the United States Government.' Title 17 USC \$101 defines a US Government work as a work prepared by a military service member or employee of the US Government as part of that person's official duties. The work of authors affiliated with the Naval Medical Research Center was supported by work unit number 6000.RAD1.F.A0309. Major funding for this work was provided by USAID, the Military Infectious Diseases Research Program, and the Congressionally Directed Medical Research Program. DLD was supported by a Pfizer Australia Senior Research Fellowship. The study protocol for the clinical trial presented in this manuscript was approved by the National Naval Medical Center, Naval Medical Research Center and Walter Reed Army Institute of Research Institutional Review Boards, in compliance with all applicable federal regulations governing protection of human subjects. All study subjects gave written informed consent. The views expressed in this article are those of the authors and do not necessarily reflect the official policy or position of the Department of the Navy, the Department of the Army, the Department of Defense, or the US Government. We gratefully acknowledge the assistance of Jennifer $\mathrm{Ng}$ in the HLA typing of the research subjects.

\section{Author details}

${ }^{1}$ US Military Malaria Vaccine Program, Naval Medical Research Center, Walter Reed Army Institute of Research, Silver Spring, MD, USA. 'La Jolla Institute for Allergy and Immunology, La Jolla, CA, USA. ${ }^{3}$ Queensland Institute of Medical Research, Brisbane, Queensland, Australia. ${ }^{4}$ USAID, Washington, DC, USA.

Received: 2 March 2013 Accepted: 23 May 2013

Published: 5 June 2013

\section{References}

1. Moorthy VS, Ballou WR: Immunological mechanisms underlying protection mediated by RTS,S: a review of the available data. Malar J 2009, 8:312. 
2. Sun P, Schwenk R, White K, Stoute JA, Cohen J, Ballou WR, Voss G, Kester KE, Heppner DG, Krzych U: Protective immunity induced with malaria vaccine, RTS, S, is linked to Plasmodium falciparum circumsporozoite proteinspecific CD4+ and CD8+ T cells producing IFN-gamma. J Immuno/ 2003, 171:6961-6967.

3. Reyes-Sandoval A, Wyllie DH, Bauza K, Milicic A, Forbes EK, Rollier CS, Hill AV: CD8+ T effector memory cells protect against liver-stage malaria. J Immunol 2011, 187:1347-1357.

4. Coppi A, Natarajan R, Pradel G, Bennett BL, James ER, Roggero MA, Corradin $G$, Persson C, Tewari R, Sinnis P: The malaria circumsporozoite protein has two functional domains, each with distinct roles as sporozoites journey from mosquito to mammalian host. J Exp Med 2011, 208:341-356.

5. Bongfen SE, Torgler R, Romero JF, Renia L, Corradin G: Plasmodium bergheiinfected primary hepatocytes process and present the circumsporozoite protein to specific CD8+ T cells in vitro. J Immunol 2007, 178:7054-7063.

6. Limbach KJ, Richie TL: Viral vectors in malaria vaccine development. Parasite Immunol 2009, 31:501-519.

7. Sedegah M, Tamminga C, McGrath S, House B, Ganeshan H, Lejano J, Abot E, Banania G, Sayo R, Farooq F, Belmonte M, Manohar N, Richie NO, Wood C, Long CA, Regis D, Williams FT, Shi M, Chuang I, Spring M, Epstein JE, Mendoza-Silveiras J, Limbach K, Patterson NB, Bruder JT, Doolan DL, King CR, Soisson L, Diggs C, Carucci D, Dutta S, Hollingdale MR, Ockenhouse CF, Richie TL: Adenovirus 5vectored $P$. falciparum vaccine expressing CSP and AMA1. Part a: safety and immunogenicity in seronegative adults. PLoS One 2011, 6:e24586.

8. Tamminga C, Sedegah M, Regis D, Chuang I, Epstein JE, Spring M, Mendoza-Silveiras J, McGrath S, Maiolatesi S, Reyes S, Steinbeiss V, Fedders C, Smith K, House B, Ganeshan H, Lejano J, Abot E, Banania GJ, Sayo R, Farooq F, Belmonte M, Murphy J, Komisar J, Williams J, Shi M, Brambilla D, Manohar N, Richie NO, Wood C, Limbach K, Patterson NB, Bruder JT, Doolan DL, King CR, Diggs C, Soisson L, Carucci D, Levine G, Dutta S, Hollingdale MR, Ockenhouse CF, Richie TL: Adenovirus-5-vectored $P$. falciparum vaccine expressing CSP and AMA1. Part B: Safety, immunogenicity and protective efficacy of the CSP component. PLoS One 2011, 6:e25868.

9. Tamminga C, Sedegah M, Maiolatesi S, Fedders C, Reyes S, Reyes A, Vasquez C, Alcorta Y, Chuang I, Spring M, et al: Human adenovirus 5-vectored plasmodium falciparum NMRC-M3V-Ad-PfCA vaccine encoding CSP and AMA1 is safe, well tolerated and immunogenic but does not protect against controlled human malaria infection. Hum Vaccin Immunother 2013. In press.

10. Frahm N, DeCamp AC, Friedrich DP, Carter DK, Defawe OD, Kublin JG, Casimiro DR, Duerr A, Robertson MN, Buchbinder SP, Huang Y, Spies GA, De Rosa SC, McElrath MJ: Human adenovirus-specific T cells modulate HIVspecific T cell responses to an Ad5-vectored HIV-1 vaccine. J Clin Invest 2012, 122:359-367.

11. Silvie O, Franetich JF, Charrin S, Mueller MS, Siau A, Bodescot M, Rubinstein E, Hannoun L, Charoenvit Y, Kocken CH, Thomas AW, Van Gemert GJ, Sauerwein RW, Blackman MJ, Anders RF, Pluschke G, Mazier D: A role for apical membrane antigen 1 during invasion of hepatocytes by Plasmodium falciparum sporozoites. J Biol Chem 2004, 279:9490-9496.

12. Chuang I, Sedegah M, Cicatelli S, Spring M, Polhemus M, Tamminga C, Patterson N, Guerrero M, Bennett JW, McGrath MG, Ganeshan H, Belmonte M, Farooq F, Abot E, Banania JG, Huang J, Newcomer R, Rein L, Litilit D, Richie NO, Wood C, Murphy J, Sauerwein R, Hermsen CC, McCoy AJ, Kamau E, Cummings J, Komisar J, Sutamihardja A, Shi M, Epstein JE, Maiolatesi S, Tosh D, Limbach K, Angov E, Bergmann-Leitner E, Bruder J, Doolan DL, King CR, Carucci D, Dutta S, Soisson L, Diggs C, Hollingdale MR, Ockenhouse CF, Richie TL: DNA prime/adenovirus boost malaria vaccine encoding $P$. falciparum CSP and AMA1 induces sterile protection associated with cell-mediated immunity. PLoS One 2013, 8:e55571.

13. Nielsen M, Lundegaard C, Worning P, Lauemoller SL, Lamberth K, Buus S, Brunak S, Lund O: Reliable prediction of T-cell epitopes using neural networks with novel sequence representations. Protein Sci 2003, 12:1007-1017.

14. Sedegah M, Kim Y, Peters B, McGrath S, Ganeshan H, Lejano J, Abot E, Banania G, Belmonte M, Sayo R, Faroog F, Doolan DL, Regis D, Tamminga C, Chuang I, Bruder JT, King CR, Ockenhouse CF, Faber B, Remarque E, Hollingdale MR, Richie TL, Sette A: Identification and localization of minimal MHC-restricted CD8+ T cell epitopes within the Plasmodium falciparum AMA1 protein. Malar J 2011, 9:241

15. Plassmeyer ML, Reiter K, Shimp RL Jr, Kotova S, Smith PD, Hurt DE, House B, Zou X, Zhang Y, Hickman M, Uchime O, Herrera R, Nguyen V, Glen J, Lebowitz J, Jin AJ, Miller LH, MacDonald NJ, Wu Y, Narum DL: Structure of the Plasmodium falciparum circumsporozoite protein, a leading malaria vaccine candidate. J Biol Chem 2009, 284:26951-26963.
16. Zeeshan M, Alam MT, Vinayak S, Bora H, Tyagi RK, Alam MS, Choudhary V, Mittra P, Lumb V, Bharti PK, Udhayakumar V, Singh N, Jain V, Singh PP, Sharma YD: Genetic variation in the Plasmodium falciparum circumsporozoite protein in India and its relevance to RTS, S malaria vaccine. PLoS One 2012, 7:e43430.

17. Stoute JA, Slaoui M, Heppner DG, Momin P, Kester KE, Desmons P, Wellde BT, Garcon N, Krzych U, Marchand M: A preliminary evaluation of a recombinant circumsporozoite protein vaccine against plasmodium falciparum malaria. RTS, S malaria vaccine evaluation group. N Engl J Med 1997, 336:86-91.

18. Heppner DG Jr, Kester KE, Ockenhouse CF, Tornieporth N, Ofori O, Lyon JA, Stewart VA, Dubois $\mathrm{P}$, Lanar DE, Krzych U, Moris P, Angov E, Cummings JF, Leach A, Hall BT, Dutta S, Schwenk R, Hillier C, Barbosa A, Ware LA, Nair L, Darko CA, Withers MR, Ogutu B, Polhemus ME, Fukuda M, Pichyangkul S, Gettyacamin M, Diggs C, Soisson L, Milman J, Dubois MC, Garçon N, Tucker K, Wittes J, Plowe CV, Thera MA, Duombo OK, Pau MG, Goudsmit J, Ballou WR, Cohen J: Towards an RTS, S-based, multi-stage, multi-antigen vaccine against falciparum malaria: progress at the Walter reed army institute of research. Vaccine 2005, 23:2243-2250.

19. Good MF, Pombo D, Quakyi IA, Riley EM, Houghten RA, Menon A, Alling DW, Berzofsky JA, Miller LH: Human T-cell recognition of the circumsporozoite protein of Plasmodium falciparum: immunodominant T-cell domains map to the polymorphic regions of the molecule. Proc Natl Acad Sci USA 1988, 85:1199-1203.

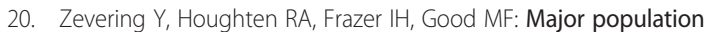
differences in T cell response to a malaria sporozoite vaccine candidate. Int Immunol 1990, 2:945-955.

21. Doolan DL, Southwood S, Chesnut R, Appella E, Gomez E, Richards A, Higashimoto YI, Maewal A, Sidney J, Gramzinski RA, Mason C, Koech D, Hoffman SL, Sette A: HLA-DR-promiscuous T cell epitopes from Plasmodium falciparum pre-erythrocytic-stage antigens restricted by multiple HLA class II alleles. J Immunol 2000, 165:1123-1137.

22. Lockyer MJ, Marsh K, Newbold Cl: Wild isolates of Plasmodium falciparum show extensive polymorphism in T cell epitopes of the circumsporozoite protein. Mol Biochem Parasitol 1989, 37:275-280

23. Sinigaglia F, Guttinger M, Gillessen D, Doran DM, Takacs B, Matile H, Trzeciak A, Pink JR: Epitopes recognized by human T lymphocytes on malaria circumsporozoite protein. Eur J Immunol 1988, 18:633-636.

24. Doolan DL, Hoffman SL, Southwood S, Wentworth PA, Sidney J, Chesnut RW, Keogh E, Appella E, Nutman TB, Lal AA, Gordon DM, Oloo A, Sette A Degenerate cytotoxic $T$ cell epitopes from $P$. falciparum restricted by multiple HLA-A and HLA-B supertype alleles. Immunity 1997, 7:97-112.

25. Wang R, Doolan DL, Le TP, Hedstrom RC, Coonan KM, Charoenvit $Y$, Jones TR, Hobart P, Margalith M, Ng J, Weiss WR, Sedegah M, de Taisne C, Norman JA, Hoffman SL: Induction of antigen-specific cytotoxic T Iymphocytes in humans by a malaria DNA vaccine. Science 1998, 282:476-480.

26. Blum-Tirouvanziam U, Servis C, Habluetzel A, Valmori D, Men Y, Esposito F, Del Nero L, Holmes N, Fasel N, Corradin G: Localization of HLA-A2.1restricted $\mathrm{T}$ cell epitopes in the circumsporozoite protein of Plasmodium falciparum. J Immunol 1995, 154:3922-3931.

27. Aidoo M, Lalvani A, Allsopp CE, Plebanski M, Meisner SJ, Krausa P, Browning M, Morris-Jones S, Gotch F, Fidock DA, Druilhe P, Takiguchi M: Identification of conserved antigenic components for a cytotoxic T lymphocyteinducing vaccine against malaria. Lancet 1995, 345:1003-1007.

28. Hill AV, Elvin J, Willis AC, Aidoo M, Allsopp CE, Gotch FM, Gao XM, Takiguchi M, Greenwood BM, Townsend AR, McMichael AJ, Whittle HC: Molecular analysis of the association of HLA-B53 and resistance to severe malaria. Nature 1992, 360:434-439.

29. Gilbert SC, Plebanski M, Harris SJ, Allsopp CE, Thomas R, Layton GT, Hill AV: A protein particle vaccine containing multiple malaria epitopes. Nat Biotechnol 1997, 15:1280-1284.

30. Dodoo D, Hollingdale MR, Anum D, Koram KA, Gyan B, Akanmori BD, Ocran J, Adu-Amankwah S, Geneshan H, Abot E, Legano J, Banania G, Sayo R, Brambilla D, Kumar S, Doolan DL, Rogers WO, Epstein J, Richie TL, Sedegah M: Measuring naturally acquired immune responses to candidate malaria vaccine antigens in Ghanaian adults. Malar J 2011, 10:168.

31. Sette A, Sidney J: Nine major HLA class I supertypes account for the vast preponderance of HLA-A and -B polymorphism. Immunogenetics 1999, 50:201-212.

32. Sette A, Sidney J: HLA supertypes and supermotifs: a functional perspective on HLA polymorphism. Curr Opin Immunol 1998, 10:478-482. 
33. Sidney J, Peters B, Frahm N, Brander C, Sette A: HLA class I supertypes: a revised and updated classification. BMC Immunol 2008, 9:1.

34. Sette A, Vitiello A, Reherman B, Fowler P, Nayersina R, Kast WM, Melief CJ, Oseroff C, Yuan L, Ruppert J, Sidney J, del Guercio MF, Southwood S, Kubo RT, Chesnut RW, Grey HM, Chisari FV: The relationship between class I binding affinity and immunogenicity of potential cytotoxic $\mathrm{T}$ cell epitopes. J Immunol 1994, 153:5586-5592.

35. Doolan DL, Southwood S, Freilich DA, Sidney J, Graber NL, Shatney L, Bebris L, Florens L, Dobano C, Witney AA, Appella E, Hoffman SL, Yates JR 3rd, Carucci DJ, Sette A: Identification of Plasmodium falciparum antigens by antigenic analysis of genomic and proteomic data. Proc Natl Acad Sci USA 2003, 100:9952-9957.

36. Vita R, Zarebski L, Greenbaum JA, Emami H, Hoof I, Salimi N, Damle R, Sette A, Peters B: The immune epitope database 2.0. Nucleic Acids Res 2013, 38(Database issue):D854-862

37. Panina-Bordignon P, Tan A, Termijtelen A, Demotz S, Corradin G, Lanzavecchia A: Universally immunogenic T cell epitopes: promiscuous binding to human MHC class II and promiscuous recognition by T cells. Eur J Immunol 1989, 19:2237-2242.

38. Frahm N, Korber BT, Adams CM, Szinger JJ, Draenert R, Addo MM, Feeney ME, Yusim K, Sango K, Brown NV, SenGupta D, Piechocka-Trocha A, Simonis T, Marincola FM, Wurcel AG, Stone DR, Russell CJ, Adolf P, Cohen D, Roach T, StJohn A, Khatri A, Davis K, Mullins J, Goulder PJ, Walker BD, Brander C: Consistent cytotoxic-T-lymphocyte targeting of immunodominant regions in human immunodeficiency virus across multiple ethnicities. J Virol 2004, 78:2187-2200.

39. Frahm N, Yusim K, Suscovich TJ, Adams S, Sidney J, Hraber P, Hewitt HS, Linde $\mathrm{CH}$, Kavanagh DG, Woodberry T, Henry LM, Faircloth K, Listgarten J, Kadie C, Jojic N, Sango K, Brown NV, Pae E, Zaman MT, Bihl F, Khatri A, John M, Mallal S, Marincola FM, Walker BD, Sette A, Heckerman D, Korber BT, Brander C: Extensive HLA class I allele promiscuity among viral CTL epitopes. Eur J Immunol 2007, 37:2419-2433.

40. Rao X, Hoof I, Costa Al, van Baarle D, Kesmir C: HLA class I allele promiscuity revisited. Immunogenetics 2011, 63:691-701.

41. Wang R, Epstein J, Baraceros FM, Gorak EJ, Charoenvit Y, Carucci DJ, Hedstrom RC, Rahardjo N, Gay T, Hobart P, Stout R, Jones TR, Richie TL, Parker SE, Doolan DL, Norman J, Hoffman SL: Induction of CD4(+) T cell-dependent $\mathrm{CD} 8(+)$ type 1 responses in humans by a malaria DNA vaccine. Proc Natl Acad Sci USA 2001, 98:10817-10822.

42. Currier JR, Kuta EG, Turk E, Earhart LB, Loomis-Price L, Janetzki S, Ferrari G, Birx DL, Cox JH: A panel of MHC class I restricted viral peptides for use as a quality control for vaccine trial ELISPOT assays. I Immunol Methods 2002, 260:157-172.

43. Sette A, Sidney J, del Guercio MF, Southwood S, Ruppert J, Dahlberg C, Grey HM, Kubo RT: Peptide binding to the most frequent HLA-A class I alleles measured by quantitative molecular binding assays. Mol Immunol 1994, 31:813-822.

44. Lund $\mathrm{O}$, Nielsen M, Kesmir C, Petersen AG, Lundegaard C, Worning P, Sylvester-Hvid C, Lamberth K, Roder G, Justesen S, Buus S, Brunak S: Definition of supertypes for HLA molecules using clustering of specificity matrices. Immunogenetics 2004, 55:797-810.

45. Doud MB, Koksal AC, Mi LZ, Song G, Lu C, Springer TA: Unexpected fold in the circumsporozoite protein target of malaria vaccines. Proc Natl Acad Sci USA 2012, 109(20):7817-7822.

46. Calvo-Calle JM, Hammer J, Sinigaglia F, Clavijo P, Moya-Castro ZR, Nardin EH: Binding of malaria T cell epitopes to DR and DQ molecules in vitro correlates with immunogenicity in vivo: identification of a universal T cell epitope in the Plasmodium falciparum circumsporozoite protein. J Immunol 1997, 159(3):1362-1373.

47. Hill AV, Allsopp CE, Kwiatkowski D, Anstey NM, Twumasi P, Rowe PA, Bennett S, Brewster D, McMichael AJ, Greenwood BM: Common west African HLA antigens are associated with protection from severe malaria. Nature 1991, 352(6336):595-600.

48. Lundegaard C, Lamberth K, Harndahl M, Buus S, Lund O, Nielsen M: NetMHC-3.0: accurate web accessible predictions of human, mouse and monkey MHC class I affinities for peptides of length 8-11. Nucleic Acids Res 2008, 36(Web Server issue):W509-512.

49. Vaughan K, Blythe M, Greenbaum J, Zhang Q, Peters B, Doolan DL, Sette A: Meta-analysis of immune epitope data for all Plasmodia: overview and applications for malarial immunobiology and vaccine-related issues. Parasite Immunol 2009, 31(2):78-97.
50. Chicz RM, Urban RG, Gorga JC, Vignali DA, Lane WS, Strominger JL: Specificity and promiscuity among naturally processed peptides bound to HLA-DR alleles. J Exp Med 1993, 178(1):27-47.

51. Lin HH, Ray S, Tongchusak S, Reinherz EL, Brusic V: Evaluation of MHC class I peptide binding prediction servers: applications for vaccine research. BMC Immunol 2008, 9:8.

52. Sidney J, del Guercio MF, Southwood S, Engelhard VH, Appella E, Rammensee HG, Falk K, Rotzschke O, Takiguchi M, Kubo RT, et al: Several HLA alleles share overlapping peptide specificities. J Immunol 1995, 154(1):247-259.

53. Sidney J, Grey HM, Southwood S, Celis E, Wentworth PA, del Guercio MF, Kubo RT, Chesnut RW, Sette A: Definition of an HLA-A3-like supermotif demonstrates the overlapping peptide-binding repertoires of common HLA molecules. Hum Immunol 1996, 45(2):79-93.

54. Sidney J, Southwood S, del Guercio MF, Grey HM, Chesnut RW, Kubo RT, Sette A: Specificity and degeneracy in peptide binding to HLA-B7-like class I molecules. J Immunol 1996, 157(8):3480-3490.

55. Escalante AA, Grebert HM, Isea R, Goldman IF, Basco L, Magris M, Biswas S, Kariuki S, Lal AA: A study of genetic diversity in the gene encoding the circumsporozoite protein (CSP) of Plasmodium falciparum from different transmission areas-XVI. Asembo Bay Cohort Project. Mol Biochem Parasitol 2002, 125(1-2):83-90.

56. Zevering Y, Khamboonruang C, Good MF: Human and murine T-cell responses to allelic forms of a malaria circumsporozoite protein epitope support a polyvalent vaccine strategy. Immunology 1998, 94(3):445-454.

57. Thera MA, Doumbo OK, Coulibaly D, Diallo DA, Kone AK, Guindo AB, Traore K, Dicko A, Sagara I, Sissoko MS, et al: Safety and immunogenicity of an AMA-1 malaria vaccine in Malian adults: results of a phase 1 randomized controlled trial. PloS one 2008, 3(1):e1465.

58. Gandhi K, Thera MA, Coulibaly D, Traore K, Guindo AB, Doumbo OK, TakalaHarrison S, Plowe CV: Next generation sequencing to detect variation in the Plasmodium falciparum circumsporozoite protein. Am J Trop Med Hyg 2012, 86(5):775-781.

59. Bailey JA, Mvalo T, Aragam N, Weiser M, Congdon S, Kamwendo D, Martinson F, Hoffman I, Meshnick SR, Juliano JJ: Use of massively parallel pyrosequencing to evaluate the diversity of and selection on Plasmodium falciparum csp T-cell epitopes in Lilongwe, Malawi. $J$ Infect Dis 2012, 206(4):580-587.

60. Diez-Rivero CM, Reche PA: CD8 T cell epitope distribution in viruses reveals patterns of protein biosynthesis. PloS one 2012, 7(8):e43674

61. Hollingdale MR: Biology and immunology of sporozoite invasion of liver cells and exoerythrocytic development of malaria parasites. Prog Allergy 1988, 41:15-48.

62. Tenzer S, Wee E, Burgevin A, Stewart-Jones G, Friis L, Lamberth K, Chang $\mathrm{CH}$, Harndahl M, Weimershaus M, Gerstoft J, et al: Antigen processing influences HIV-specific cytotoxic T lymphocyte immunodominance. Nat Immunol 2009, 10(6):636-646

\section{doi:10.1186/1475-2875-12-185}

Cite this article as: Sedegah et al: Identification of minimal human MHC-restricted CD8+ T-cell epitopes within the Plasmodium falciparum circumsporozoite protein (CSP). Malaria Journal 2013 12:185.

\section{Submit your next manuscript to BioMed Central and take full advantage of:}

- Convenient online submission

- Thorough peer review

- No space constraints or color figure charges

- Immediate publication on acceptance

- Inclusion in PubMed, CAS, Scopus and Google Scholar

- Research which is freely available for redistribution 